\title{
The Emergence of a Stable Neuronal Ensemble from a Wider Pool of Activated Neurons in the Dorsal Medial Prefrontal Cortex during Appetitive Learning in Mice
}

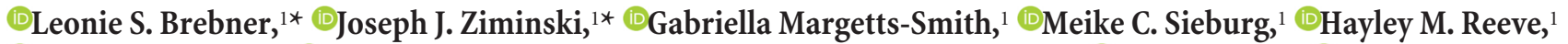

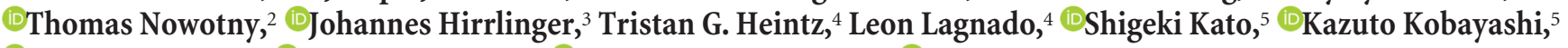

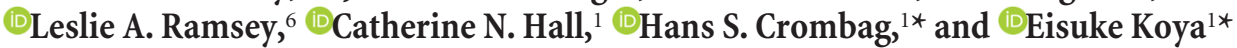 \\ ${ }^{1}$ Sussex Neuroscience, School of Psychology, University of Sussex, Falmer, BN1 9QG, United Kingdom, ${ }^{2}$ Sussex Neuroscience, School of Engineering and \\ Informatics, University of Sussex, Falmer, BN1 9QJ, United Kingdom, ${ }^{3}$ Carl-Ludwig-Institute for Physiology, University of Leipzig, D-04103, Leipzig, \\ Germany, and Department of Neurogenetics, Max-Planck-Institute for Experimental Medicine, D-37075, Göttingen, Germany, ${ }^{4}$ Sussex Neuroscience, \\ School of Life Sciences, University of Sussex, Falmer, BN1 9QG, United Kingdom, ${ }^{5}$ Department of Molecular Genetics, Institute of Biomedical Sciences, \\ Fukushima Medical University School of Medicine, Fukushima 960-1295, Japan, and 'Behavioral Neuroscience Branch, Intramural Research Program/ \\ National Institute on Drug Abuse/National Institutes of Health/Department of Health and Human Services, Baltimore, Maryland 21224
}

Animals selectively respond to environmental cues associated with food reward to optimize nutrient intake. Such appetitive conditioned stimulus- unconditioned stimulus (CS-US) associations are thought to be encoded in select, stable neuronal populations or neuronal ensembles, which undergo physiological modifications during appetitive conditioning. These ensembles in the medial prefrontal cortex (mPFC) control well-established, cue-evoked food seeking, but the mechanisms involved in the genesis of these ensembles are unclear. Here, we used male Fos-GFP mice that express green fluorescent protein (GFP) in recently behaviorally activated neurons, to reveal how dorsal mPFC neurons are recruited and modified to encode CS-US memory representations using an appetitive conditioning task. In the initial conditioning session, animals did not exhibit discriminated, cue-selective food seeking, but did so in later sessions indicating that a CS-US association was established. Using microprism-based in vivo 2-Photon imaging, we revealed that only a minority of neurons activated during the initial session was consistently activated throughout subsequent conditioning sessions and during cue-evoked memory recall. Notably, using ex vivo electrophysiology, we found that neurons activated following the initial session exhibited transient hyperexcitability. Chemogenetically enhancing the excitability of these neurons throughout subsequent conditioning sessions interfered with the development of reliable cue-selective food seeking, indicated by persistent, nondiscriminated performance. We demonstrate how appetitive learning consistently activates a subset of neurons to form a stable neuronal ensemble during the formation of a CS-US association. This ensemble may arise from a pool of hyperexcitable neurons activated during the initial conditioning session.

Key words: appetitive conditioning; food seeking; Fos; in vivo imaging; neuronal ensembles; medial prefrontal cortex

Significance Statement

Appetitive conditioning endows cues associated with food with the ability to guide food-seeking, through the formation of a food-cue association. Neuronal ensembles in the mPFC control established cue-evoked food-seeking. However, how neurons undergo physiological modifications and become part of an ensemble during conditioning remain unclear. We found that only a minority of dorsal mPFC neurons activated on the initial conditioning session became consistently activated during conditioning and memory recall. These initially activated neurons were also transiently hyperexcitable. We demonstrate the following: (1) how stable neuronal ensemble formation in the dorsal mPFC underlies appetitive conditioning; and (2) how this ensemble may arise from hyperexcitable neurons activated before the establishment of cue-evoked food seeking. 


\section{Introduction}

Through Pavlovian associative learning, a conditioned stimulus (CS) that reliably predicts food reward (unconditioned stimulus [US]) is endowed with motivational significance and the ability to activate and retrieve food memories (Pavlov, 1927; Jansen, 1998; van den Akker et al., 2018). These CS-activated food representations can elicit actions to facilitate food procurement. For animals, this maximizes caloric intake while minimizing time and energy spent searching for food (MacArthur and Pianka, 1966; Carthey et al., 2011). In humans, food-associated cues can elicit food cravings and produce eating in the absence of hunger, which may contribute to eating disorders involving binge eating (Jansen, 1998; van den Akker et al., 2018). Elucidating the neurobiological mechanisms underlying the establishment of appetitive CS-US associations is important for understanding both adaptive and maladaptive eating (Jansen, 1998; van den Akker et al., 2018).

The motivational functions of CS-activated memory representations involve activation of sparse sets of neurons or "neuronal ensembles" in the medial prefrontal cortex (mPFC), a brain region implicated in various appetitive behaviors (Koya et al., 2009; Cruz et al., 2013; Riga et al., 2014; Suto et al., 2016; Whitaker and Hope, 2018). Accordingly, selective silencing of mPFC ensembles attenuates cue-evoked food-seeking (Suto et al., 2016). These findings offer compelling evidence that CSactivated mPFC ensembles stably encode associative memories that elicit and guide appetitive performance. The establishment of an appetitive CS-US association is readily examined using a Pavlovian conditioning task. In the initial conditioning sessions, animals do not exhibit discriminated cue-evoked food seeking, but in later sessions this behavior becomes more discriminated, indicating an establishment of a CS-US association (Ziminski et al., 2017). However, we have yet to understand how CS-US encoding neuronal ensembles are formed as these associations become established (i.e., as a function of conditioning).

We addressed this issue here by visualizing ensemble formation and activation patterns across conditioning sessions using microprism-based 2-Photon (2P) in vivo imaging (Low et al., 2014). Unlike conventional cranial window $2 \mathrm{P}$ imaging, using a microprism allowed us to access the mPFC. We focused on the anterior cingulate cortex (ACC) region of the dorsal mPFC

Received June 26, 2019; revised Nov. 4, 2019; accepted Nov. 6, 2019.

Author contributions: L.S.B., J.J.Z., T.G.H., L.L., C.N.H., H.S.C., and E.K. designed research; L.S.B., J.J.Z., G.M.-S., M.C.S., H.M.R., L.A.R., and E.K. performed research; L.S.B., J.J.Z., G.M.-S., T.N., C.N.H., H.S.C., and E.K. analyzed data; L.S.B. and J.J.Z. wrote the first draft of the paper; L.S.B., J.J.Z., G.M.-S., M.C.S., H.M.R., T.N., J.H., T.G.H., L.L., S.K., K.K., L.A.R., C.N.H., H.S.C., and E.K. edited the paper; L.S.B., J.J.Z., G.M.-S., H.S.C., and E.K. wrote the paper; J.H., S.K., and K.K. contributed unpublished reagents/analytic tools.

This work was supported by the Biotechnology and Biological Sciences Research Council Grant BB/M009017/1, MRC Discovery Award, University of Sussex Strategic Development Funds, Sussex Neuroscience 4-year PhD programme, and the Intramural Research Program, National Institute on Drug Abuse, National Institutes of Health. We thank Prof. William Wisden (Imperial College) for providing the initial AAV2-TREtight-hM3Dq sample for the DREADD pilot experiments; Dr. Marsha Sindarto (University of Sussex) for providing helpful advice with the generation of the aforementioned viruses; Nagisa Sawada (Fukushima Medical University) for providing assistance with AAV generation; Alex Hoffman (National Institute on Drug Abuse Intramural Research Program) for providing helpful advice regarding the paired recording experiments; Bruce Hope (National Institute on Drug Abuse Intramural Research Program) for providing additional Fos-GFP mice brains for analysis; and Nobuyoshi Suto (Scripps Research) for helpful comments with the manuscript.

The authors declare no competing financial interests.

*L.S.B., J.J.Z., H.S.C., and E.K. contributed equally to this work.

Correspondence should be addressed to Eisuke Koya at e.koya@sussex.ac.uk.

G. Margetts-Smith's present address: University of Exeter College of Medicine and Health, Hatherly Laboratories, Prince of Wales Road, Exeter EX4 4PS, United Kingdom.

Meike C. Sieburg's present address: Department of Biomedicine/DANDRITE, Aarhus University, 8000 Aarhus C, Denmark.

https://doi.org/10.1523/JNEUROSCI.1496-19.2019

Copyright $\odot 2020$ the authors
(dmPFC) because it plays a role in facilitating attentional processes and discriminating between food-predictive and nonpredictive cues (Parkinson et al., 2000; Cardinal et al., 2002; Totah et al., 2009; Bryden et al., 2011). Furthermore, we crossed Fos-GFP and GAD-tdTomato mice to generate Fos-GFP $\times$ GAD-tdTomato (FGGT) mice. These mice express GFP in recently behaviorally activated $\left(\mathrm{GFP}^{+}\right)$neurons with a similar time course to the acute neuronal activity marker Fos (Barth et al., 2004; Whitaker et al., 2016; Ziminski et al., 2017). Also, they express the red fluorescent protein tdTomato in interneurons (Besser et al., 2015). This enabled us to selectively track activation patterns of pyramidal cells $\left(\right.$ tdTomato $^{-}$) and interneurons (tdTomato ${ }^{+}$) across learning and recall sessions in mice trained on a Pavlovian appetitive conditioning task.

Physiological adaptations in CS-activated ensembles are thought to play a role in establishing associative memories; changes in appetitive associative strength modulate ensemble excitability (Whitaker et al., 2017; Ziminski et al., 2017), whereas the formation of an appetitive association induces synaptic remodeling in an ensemble-specific manner (Whitaker et al., 2016). Similarly, fear conditioning studies have identified a critical role of increased synaptic strength and connectivity between learning-activated neurons in the establishment of aversive associative memories (Ryan et al., 2015; Choi et al., 2018). However, we do not know how similar physiological alterations shape recruitment of neuronal ensembles in the dmPFC that encode appetitive CS-US associations. Hence, we compared changes in excitability, synaptic physiology, and connectivity of behaviorally activated neurons during the early stages (i.e., before the establishment of robust CS-evoked food seeking) and late stages of conditioning. Finally, we directly tested the importance of neuronal excitability changes in conditioned performance using a chemogenetic (designer receptor exclusively activated by designer drugs [DREADD]) approach.

\section{Materials and Methods}

Animals

Heterozygous (het) male Fos-GFP (RRID:IMSR_JAX:014135), Fos-tTa (RRID:MMRRC_031756-MU), GAD-tdTomato mice (RRID:IMSR_EM: 10422) (Besser et al., 2015) mice were bred onto a C57BL/6 background. TRE-H2B-GFP (RRID:IMSR_JAX:005104) (Tumbar et al., 2004) mice previously bred onto a CD-1 background were bred with WT C57BI/6 females obtained from Charles River at the University of Sussex. het TRE-H2B-GFP mice were bred onto a C57BL/6 background for at least 6 generations before being bred with het Fos- $t$ TA mice to generate doubletransgenic TetTag H2B-GFP mice. Het male GAD-tdTomato were bred with het Fos-GFP female mice to produce double-transgenic Fos-GFP $\times$ GAD-tdTomato (FGGT) mice. The Fos-GFP het male mice used to characterize the time course of Fos-GFP expression (see Fig. 2) were bred in a similar manner at the National Institute on Drug Abuse Intramural Research Program (Bruce Hope laboratory, Baltimore). FGGT male mice were used for $2 \mathrm{P}$ imaging experiments (Experiment 1), Fos-GFP and TetTag H2B-GFP male mice were used for ex vivo electrophysiology experiments (Experiment 2). Fos-tTa and WT male mice were used for chemogenetics experiments (Experiment 3). All mice were housed under a $12 \mathrm{~h}$ light/dark cycle (lights on at 7:00 A.M.) at the maintained temperature of $21 \pm 1{ }^{\circ} \mathrm{C}$ and $50 \pm 5 \%$ relative humidity. Mice used in the Fos-GFP expression time course experiment were $\sim 20-25$ weeks old at the time of testing. For Experiments 1-3, mice were 7-13 weeks of age at the beginning of experimental procedures and were food restricted $(90 \%$ baseline body weight) 1 week before behavioral testing until the completion of behavioral experiments. The Fos-GFP expression time course experiment was performed according to National Institutes of Health guidelines under experimental protocols that were approved by the Animal Care and Use Committee of National Institute on Drug Abuse In- 
tramural Research Program. Experiments 1-3 were conducted in accordance with the UK 1986 Animal Scientific Procedures Act and received approval from the University of Sussex Animal Welfare and Ethics Review Board.

\section{Surgical procedures}

Microprism implantation in FGGT mice (Experiment 1). At ages 10-13 weeks, FGGT mice were implanted with a microprism in the mPFC. Microprism constructs were built by assembling 2 circular glass windows (5 and $3 \mathrm{~mm}$ diameter; \#1 thickness, catalog \#64-0700 and 64-0720, Warner Instruments) and a $1.5 \mathrm{~mm}$-coated microprism (model MPCH1.5, part \#4531-0023, Tower Optics) using optical glue (Norland Optical Adhesive), such that the microprism rested on the $3 \mathrm{~mm}$ window with its vertical imaging edge on the diameter. Mice were anesthetized with isoflurane $3 \%$ dilution in $\mathrm{O}_{2}(0.8 \mathrm{~L} / \mathrm{min})$ and $\mathrm{NO}_{2}(0.5 \mathrm{~L} / \mathrm{min})$ and maintained between $1 \%$ and $2 \%$ dilution throughout the surgery. They first received an injection of dexamethasone (Dexadreson, $5 \mathrm{mg} / \mathrm{kg}$, s.c. or i.m.) to reduce cerebral inflammation. The skin on their scalp was sectioned off, and the skin around the section was glued to the skull (Vetbond, $3 \mathrm{M}$ ). The bone was then scored before a set of custom headbars was fixed to the skull using dental cement (Unifast TRAD). A $3 \mathrm{~mm}$ circular opening was created in the skull centered at bregma $0.8 \mathrm{~mm}$ ( $\pm 0.2 \mathrm{~mm}$ according to the location of blood vessels).The final area observable through the microprism spanned approximately from bregma $0.05 \mathrm{~mm}$ to $1.55 \mathrm{~mm}$ on the rostrocaudal axis and from 0 to 1.5 $\mathrm{mm}$ on the dorsoventral axis (of note, the most dorsal section was usually obscured by the central sinus). The vast majority of this area constitutes the ACC of the mPFC (see Fig. 3A) (Paxinos and Franklin, 2001). Microprism implantation occurred similarly as described by Low et al. (2014). The dura was removed, and the microprism construct was lowered into the brain using a custom-built holder such that the microprism was positioned between the hemispheres with the imaging surface placed against the sagittal surface of one of the hemispheres (see Fig. 3A). The construct was glued with Vetbond and further fixed with dental cement. Following implantation, mice received buprenorphine $(0.1 \mu \mathrm{g} / \mathrm{kg}, \mathrm{i} . \mathrm{m}$.) and were left to recover in a heated chamber for an hour. Following surgery, they received $3 \mathrm{~d}$ of oral meloxicam (Metacam, Boehringer). All mice recovered for a minimum of 2 weeks before undergoing any further procedures. The first imaging session typically occurred 3-4 weeks following surgery to allow inflammation in the imaging area to subside.

Generation of adeno-associated virus (AAV) particles. All AAV transgenes were packaged into AAV capsids, serotype AAV2. HEK293 cells were cotransfected with the transgene construct plasmid pAAV-PTREtight-hM3Dq-mCherry, which was a gift from Prof. William Wisden (Zhang et al., 2015) (Addgene, plasmid \#66795), the adenovirus helper plasmid pHelper (Stratagene), and the AAV2 helper plasmid pRC (Stratagene) using the calcium phosphate method. The cells were harvested and pelleted $72 \mathrm{~h}$ after transfection and resuspended in lysis buffer (150 mм NaCl, 20 mм Tris, pH 8.0). Benzonase endonuclease (Merck; E1014) was added, and the cell lysate was incubated at $37^{\circ} \mathrm{C}$ for $30 \mathrm{~min}$, before being centrifuged and the supernatant purified by the iodixanol gradient method. Optiseal tubes (Beckman Coulter; 361625) were prepared with iodixanol gradients overlaid in the following order; $5 \mathrm{ml} \mathrm{15 \%}$ in PBSMK, $5 \mathrm{ml}$ 25\% in PBS-MK with phenol red, $6 \mathrm{ml} \mathrm{40 \%} \mathrm{in} \mathrm{PBS-MK,} \mathrm{and} 9$ $\mathrm{ml} 60 \%$ with phenol red. The supernatant was then overlaid and the tube sealed, then centrifuged at $461,000 \times g$ for $1 \mathrm{~h}$ at $18^{\circ} \mathrm{C}$. The AAV particles were collected from the $20 \%$ layer by piercing the tube horizontally with an 18G needle, and concentrated using Amico Ultra-4 (Merck; UFC 810008$)$ at $2000 \times g$ for a minimum of $20 \mathrm{~min}$. The elution was resuspended with $250 \mu \mathrm{l} \mathrm{dPBS}$ and aliquoted and stored at $-80^{\circ} \mathrm{C}$. The final titer was $1.67 \times 10^{10}$ copies $/ \mathrm{ml}$.

Virus microinjection in the mPFC of Fos-tTa and WT mice (Experiment 3). Seven- to 12 -week-old Fos-tTa and WT mice received bilateral injections of $\mathrm{AAV}_{2}-\mathrm{TRE}_{\text {tight }}$-hM3Dq-mCherry (Zhang et al., 2015) in the mPFC (coordinates: AP: bregma 1.2, ML $\pm 0.5, \mathrm{DV}-1.2)$. Mice were anesthetized with isoflurane $3 \%$ dilution in $\mathrm{O}_{2}(0.8 \mathrm{~L} / \mathrm{min})$ and $\mathrm{NO}_{2}(0.5$ $\mathrm{L} / \mathrm{min}$ ) and kept between $1 \%$ and $2 \%$ dilution throughout the surgery. Using a mounted drill, openings were created at the anteroposterior and mediolateral coordinates. Custom-built infusers, assembled from 26G 30 $\mathrm{mm}$ and 33G $65 \mathrm{~mm}$ stainless-steel tubes (Coopers Needle Works), were then lowered to the dorsoventral coordinates, and $0.5 \mu \mathrm{l} / \mathrm{h}$ emisphere of virus was injected at a rate of $0.1 \mu \mathrm{l} / \mathrm{min}$. The infusers remained in the brain $7 \mathrm{~min}$ before being raised gradually. Mice received meloxicam (Metacam, Boehringer) orally for $1 \mathrm{~d}$ before and $3 \mathrm{~d}$ after surgery for analgesia and reducing inflammation. A week following surgery and for the duration of the experiment, all mice received doxycycline in their drinking water $(0.1 \mathrm{mg} / \mathrm{ml})$ to prevent any unwanted transgene expression.

\section{Behavioral experiments}

General procedures (Experiment 1-3). Similar behavioral experimental procedures and apparatus were used as in Ziminski et al. (2017). Briefly, behavioral experiments were performed in standard mouse conditioning chambers $(15.9 \times 14 \times 12.7 \mathrm{~cm}$; Med Associates $)$, each fitted with a recessed magazine that dispensed $10 \%$ sucrose solution serving as the US and a mechanical click generator providing a sound, which served as a CS. An infrared beam detected head entries into the food magazine. Mice were randomly assigned to Paired or Unpaired groups that underwent identical procedures, except that Unpaired mice only received sucrose in the home cage $1-4 \mathrm{~h}$ at random times before or after each conditioning (acquisition) session. As such, this group controlled for factors such as the effects of handling, chamber, and CS and US exposure. One day following magazine training (in which Paired mice were pretrained to the sucrose delivery magazine), mice underwent 12 acquisition sessions over a $7 \mathrm{~d}$ period for 1 or 2 sessions per day. Each 25 min acquisition session consisted of six 120 s CS presentations, separated by 120 s randominterval intertrial interval (ITI) periods. During each CS period, $10 \%$ sucrose was delivered to the magazine (Paired mice) or was unrewarded (Unpaired mice) at a random-interval 30 schedule.

Experiment-specific procedures. Time course of Fos-GFP expression measured by GFP immunofluorescence: Fos-GFP mice in the 1.5, 8, and $18 \mathrm{~h}$ condition were initially exposed to a novel context (Plexiglas locomotor activity chamber, dimensions 43 (width) $\times 43$ (length) $\times 30$ (height) $\mathrm{cm}$ ) for $25 \mathrm{~min}$ and then remained in their home cages for an additional $65 \mathrm{~min}, 7 \mathrm{~h} 35 \mathrm{~min}$, and $17 \mathrm{~h} 35 \mathrm{~min}$, respectively, and were subsequently deeply anesthetized and transcardially perfused with $4 \%$ paraformaldehyde (PFA). Fos-GFP mice in the $0 \mathrm{~h}$ condition were transcardially perfused without being exposed to the novel context. GFP immunofluorescence was performed as described previously (Ziminski et al., 2017). Unless specified, all steps were performed in room temperature. The $30 \mu \mathrm{m}$ sections containing the ACC were prepared using a CM1900 cryostat (Leica Microsystems), and sections were collected in TBS (0.025 M Tris-HCl, $0.5 \mathrm{M} \mathrm{NaCl}, \mathrm{pH} 7.5)$. Free-floating sections were washed in TBS and blocked in 10\% normal goat serum (catalog \#S-1000, RRID:AB_2336615; Vector Laboratories) in TBST (TBS, 0.2\% Triton $\mathrm{X}-100)$. Next, slices were incubated at $4^{\circ} \mathrm{C}$ overnight in anti-GFP primary antibody (catalog \#ab13970, RRID:AB_300798; Abcam) diluted $1 / 16,000$ in $3 \%$ normal goat serum TBST. The following day, slices were incubated for $2 \mathrm{~h}$ in anti-chicken Alexa-488 (catalog \#A-11039, RRID: AB_2534096, Thermo Fisher Scientific) at 1/200 in TBST. Slices were mounted on Superfrost Plus slides (catalog \#10149870; Thermo Fisher Scientific), air-dried, and coverslipped with PermaFluor (catalog \#TA030-FM; Thermo Fisher Scientific).

Fluorescence images of GFP staining from left and right hemispheres of the dmPFC from two coronal sections per animal, corresponding to approximately bregma 0.7 and 1.2 (Paxinos and Franklin, 2001), were captured using a QI click camera (Qimaging) attached to an Olympus Bx53 microscope. $\mathrm{GFP}^{+}$-immunoreactive nuclei were quantified using iVision software (version 4.0.15, RRID:SCR_014786; Biovision Technologies). Layers II/III were selected for this analysis similar to our in vivo imaging and ex vivo electrophysiology experiments.

Experiment 1 (in vivo imaging). Acquisition sessions proceeded in Paired and Unpaired groups as described in General procedures with a protruding feeding port to accommodate mice equipped with a headrestraint device. For acquisition Sessions 1 (S1), 5 (S5), and 11 (S11), Unpaired mice received sucrose $10 \mathrm{~min}$ before training in their home cage; for all other sessions, sucrose was delivered at a random time during the day. Three days following the last acquisition session, mice were 
tested for Pavlovian conditioning with a cue exposure test: both Paired and Unpaired mice were placed in the conditioning chamber and tested under extinction conditions for $3 \mathrm{CS}$ presentations.

Experiment 2 (ex vivo electrophysiology). Fos-GFP mice were randomly assigned to $S 1$ and $S 11$ groups. Mice in the $S 1$ group received only a single acquisition session (Paired or Unpaired as described in General procedures) following magazine training before being killed for electrophysiology recordings. Unpaired mice received sucrose in their home cage 10 min before this session. Mice in the S11 group received 11 sessions of conditioning before being killed for electrophysiology recordings. Unpaired mice received sucrose in their home cage $10 \mathrm{~min}$ before this session; for all other sessions, it was delivered at a random time. TetTag H2B-GFP mice received only a single S1 acquisition session (Paired or Unpaired as described in General procedures) following magazine training. Likewise, Unpaired mice received sucrose $10 \mathrm{~min}$ before the session; 3-7 d following this acquisition session, they were killed for electrophysiology recordings.

Experiment 3 (chemogenetics). All mice were trained under Paired conditions, and two main experiments S1 tag and novel context (NC) tag were performed here. In both experiments, Fos-tTA and their negative, WT littermates (same genetic background) were injected with $\mathrm{AAV}_{2^{-}}$ $\mathrm{TRE}_{\text {tight }}$-hM3Dq-mCherry and underwent identical behavioral procedures, except for the tagging session, which could either be a conditioning session as described in General procedures ( $\mathrm{S} 1 \mathrm{tag}$ ) or a 25

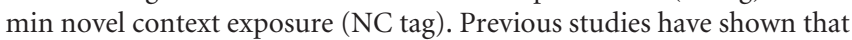
novel context exposure recruits neurons that are unrelated to appetitive learning (Cruz et al., 2014); thus, this exposure served to tag such neurons here. Immediately following Magazine training, doxycycline was removed from the drinking water for $48 \mathrm{~h}$, at which point mice underwent the tagging session to label activated neurons in Fos- $t \mathrm{Ta}$ mice with hM3Dq. Importantly, hM3Dq expression persisted many days following the acquisition and recall sessions (see Fig. $8 B$ ), indicating the reliability of our neuronal manipulation. An hour following this tagging session, mice received high doxycycline drinking water $(1 \mathrm{mg} / \mathrm{ml})$ for $24 \mathrm{~h}$ before undergoing a normal conditioning session and receiving low doxycycline drinking water $(0.1 \mathrm{mg} / \mathrm{ml})$ for the remainder of the experiment. Conditioning sessions then proceeded as described in General procedures until the completion of a total of 12 conditioning sessions. Mice received injections of the hM3Dq agonist clozapine $(0.1 \mathrm{mg} / \mathrm{kg}$, i.p.) (Gomez et al., 2017) $15 \mathrm{~min}$ before the beginning of every two sessions (see Fig. 8A). This compound is a metabolite of the widely used hM3Dq agonist clozapine- $N$-oxide; clozapine has recently been shown to serve as the agonist at hM3Dq (Gomez et al., 2017). Thus, clozapine compared with clozapine- $N$-oxide has a direct mode of action at hM3Dq and does not depend on metabolic function. To habituate mice to injections, 4 or 5 saline injections were delivered to them over the week preceding training. Three days following the last acquisition session, mice were tested for Pavlovian conditioning with a cue exposure test: Paired mice were placed in the conditioning chamber and tested under extinction conditions for 6 CS presentations.

\section{Electrophysiology (Experiment 2)}

Brain slice preparation. Ninety minutes following the initiation of S1 or S11 (Fos-GFP mice) and 3-7 d following the initiation of S1 (TetTag $H 2 B$-GFP mice), mice were deeply anesthetized with ketamine and xylazine and transcardially perfused with ice-cold NMDG-HEPES recovery aCSF (in mM as follows: $93 \mathrm{NMDG}, 2.5 \mathrm{KCl}, 1.2 \mathrm{NaH}_{2} \mathrm{PO}_{4}, 30 \mathrm{NaHCO}_{3}$, 20 HEPES, 25 glucose, 2 thiourea, $5 \mathrm{Na}$-ascorbate, 3 Na-pyruvate, 0.5 $\mathrm{CaCl}_{2} \cdot 4 \mathrm{H}_{2} \mathrm{O}$, and $10 \mathrm{MgSO}_{4} \cdot 7 \mathrm{H}_{2} \mathrm{O}$, bubbled with $95 \% \mathrm{O}_{2} / 5 \% \mathrm{CO}_{2}, \mathrm{pH}$ 7.4, 305-310 mOsm $/ \mathrm{kg}$ ) (Ting et al., 2014). The brain was quickly removed and sliced in NMDG-HEPES aCSF on a VT1200S vibratome (Leica Microsystems) to $250-\mu \mathrm{m}$-thick sections between bregma 1.70 and $0.86 \mathrm{~mm}$ containing the $\mathrm{mPFC}$. Sections were incubated in $34^{\circ} \mathrm{C}$ NMDG-HEPES aCSF for $5 \mathrm{~min}$ and transferred to standard recording aCSF (in mM as follows: $126 \mathrm{NaCl}, 4.5 \mathrm{KCl}, 1 \mathrm{MgCl}_{2}, 2.5 \mathrm{CaCl}_{2}, 1.2$ $\mathrm{NaH}_{2} \mathrm{PO}_{4} 11 \mathrm{D}-(+)$-glucose, $26 \mathrm{NaHCO}_{3}$ bubbled with $95 \% \mathrm{O}_{2} / 5 \%$ $\mathrm{CO}_{2}, \mathrm{pH}$ 7.4) at room temperature for the remainder of the recording day. Slices were transferred to a recording chamber perfused with $30^{\circ} \mathrm{C}$ $32^{\circ} \mathrm{C}$ standard aCSF at $2-3 \mathrm{ml} / \mathrm{min}$. Neurons were visualized with differ- ential interference contrast using an Olympus BX51WI microscope attached to a Revolution XD spinning disk confocal system (252, Andor Technology) for fluorescence microscopy.

$\mathrm{GFP}^{+}$neurons were identified with a $488 \mathrm{~nm}$ excitation wavelength; neurons that did not express visible GFP were considered to be GFPnegative $\left(\mathrm{GFP}^{-}\right)$. Whole-cell recordings on layers II-III dmPFC pyramidal neurons were performed using borosilicate capillary glass pipettes ( $1.5 \mathrm{~mm}$ outer diameter, $0.86 \mathrm{~mm}$ inner diameter) for intrinsic excitability and connectivity recordings filled with the following (in $\mathrm{mM}$ ): 135 K-gluconate, $3 \mathrm{MgCl}_{2}, 4 \mathrm{NaCl}, 5 \mathrm{HEPES}, 5$ EGTA, $2 \mathrm{Mg}$-ATP, $0.3 \mathrm{Na}_{3}$ GTP, pH 7.25, and $100 \mu \mathrm{M}$ Alexa-568 dye (A10437, Thermo Fisher Scientific), and for synaptic recordings (in mM: 0.1 spermine, 120 $\mathrm{CsCH}_{3} \mathrm{SO}_{3}, 5 \mathrm{NaCl}, 10$ TEA-Cl, 10 HEPES, 1.1 EGTA, 4 MgATP, 0.3 Na-GTP, 0.001 QX314 [lidocaine, Sigma-Aldrich] and 1\% biocytin [Sigma-Aldrich]). Pipette resistances ranged from 4 to $7 \mathrm{~m} \Omega$. Neurons were confirmed to be $\mathrm{GFP}^{+}$during recording by colocalization of GFP and Alexa-568. Pyramidal neurons were identified based on their morphology and/or characteristic firing properties (Cao et al., 2009). Data were collected with a Multiclamp 700B amplifier (Molecular Devices), A/D board (PCI 6024E, National Instruments), and WinWCP and WinEDR Software (courtesy of Dr. John Dempster, University of Strathclyde, Glasgow, UK; http://spider.science.strath.ac.uk/sipbs/software_ ses.htm). Signals were amplified, filtered at $4 \mathrm{kHz}$, and digitized at 10 $\mathrm{kHz}$. The Hum Bug noise eliminator (Quest Scientific) was used to reduce noise.

Intrinsic excitability recordings. Pyramidal neurons were held at -65 $\mathrm{mV}$ for the duration of recording. The current-clamp protocol consisted of $800 \mathrm{~ms}$ positive current injections from $-60 \mathrm{pA}$ incrementing in $4 \mathrm{pA}$ steps. The liquid junction potential was $-13.7 \mathrm{mV}$ and was not accounted for. Spike counts were conducted using Stimfit (Guzman et al., 2014), whereas spike kinetics were analyzed with MiniAnalysis software (Synaptosoft). For details on spike kinetic analysis, see Table 1.

Synaptic physiology recordings. Recordings were undertaken in the presence of the $\mathrm{GABA}_{\mathrm{A}}$ channel blocker picrotoxin (100 $\mu \mathrm{M}$; SigmaAldrich). sEPSCs were analyzed over a $30 \mathrm{~s}$ period with MiniAnalysis. Responses were evoked using $0.1 \mathrm{~ms}$ pulses through bipolar theta glass pipettes filled with extracellular solution, within $200 \mu \mathrm{m}$ of the neuron. Series resistance was monitored using $-10 \mathrm{mV}$ voltage steps (100 ms), and only cells maintaining stable access ( $<15 \%$ change) were included in the analyses. Paired-pulse ratios (PPRs) were calculated by stimulating twice in succession and dividing second peak by the first peak (average of triplicate), across interstimulation intervals of 20,40,60, 80, 100, 150, and $200 \mathrm{~ms}$. AMPA receptor/NMDA receptor (AMPAR/NMDAR) current ratios were calculated from the averages of 10-20 evoked EPSCs at $+40 \mathrm{mV}$ with and without D-APV (50 $\mu \mathrm{M}$, catalog \#HB0225, Hello Bio). For each neuron, the AMPAR current (with D-APV) was subtracted from the combined current (without D-APV) to yield the NMDAR current. AMPAR current peak was divided by NMDAR current peak to yield AMPAR/NMDAR ratios. Traces in figures have stimulus artifacts removed.

Connectivity recordings. Pairs of pyramidal neurons located within 60 $\mu \mathrm{m}$ were targeted for dual recordings. Single action potentials were elicited from Presynaptic neurons in current-clamp mode using a $5 \mathrm{~ms}$ step current. Postsynaptic neurons were held in voltage-clamp mode at -70 $\mathrm{mV}$. A connection was deemed present when a presynaptic AP elicited an EPSC response in at least $50 \%$ of 50 sweeps. Upon completion of recording, assessment of connectivity was conducted in the opposite direction.

\section{Histology (Experiment 3)}

Fos-tTa and WT mice were anesthetized with $200 \mathrm{mg} / \mathrm{kg}$ (i.p.) sodium pentobarbital and transcardially perfused with 4\% PFA. To assess mCherry expression, free-floating sections were washed in TBS $(0.025 \mathrm{M}$ Tris- $\mathrm{HCl}, 0.5 \mathrm{M} \mathrm{NaCl}, \mathrm{pH} 7.5$ ) and blocked in $10 \%$ normal goat serum (catalog \#S-1000, Vector Laboratories, RRID:AB_2336615) in TBST (TBS, $0.2 \%$ Triton $\mathrm{X}-100$ ). Slices were incubated at $4^{\circ} \mathrm{C}$ overnight in anti-mCherry primary antibody (catalog \#ab205402, Abcam, RRID: AB_2722769) diluted $1 / 2000$ in 3\% normal goat serum TBST. The following day, slices were incubated $2 \mathrm{~h}$ in anti-chicken 568 antibody (catalog \#20104-1, Biotium, RRID:AB_10853460) at 1/200 in TBST. 
Table 1. Passive and active membrane properties following $\mathrm{S} 1$ and $\mathrm{S} 11^{a}$

\begin{tabular}{|c|c|c|c|c|c|c|c|c|}
\hline & \multicolumn{4}{|l|}{ Session 1 (S1) } & \multicolumn{4}{|l|}{ Session 11 (S11) } \\
\hline & \multicolumn{2}{|l|}{ Unpaired } & \multicolumn{2}{|l|}{ Paired } & \multicolumn{2}{|l|}{ Unpaired } & \multicolumn{2}{|l|}{ Paired } \\
\hline & $\mathrm{GFP}^{-}$ & $\mathrm{GFP}^{+}$ & $\mathrm{GFP}^{-}$ & $\mathrm{GFP}^{+}$ & $\mathrm{GFP}^{-}$ & $\mathrm{GFP}^{+}$ & $\mathrm{GFP}^{-}$ & $\mathrm{GFP}^{+}$ \\
\hline Rheobase (pA) & $77.33 \pm 6.83$ & $103.27 \pm 18.58$ & $121.00 \pm 16.69$ & $75.14 \pm 8.24^{*}$ & $82.57 \pm 14.37$ & $79.20 \pm 5.36$ & $86.71 \pm 8.46$ & $91.37 \pm 10.26$ \\
\hline $\mathrm{R}_{\mathrm{i}}(\mathrm{m} \Omega)$ & $160.38 \pm 9.20$ & $151.10 \pm 14.11$ & $138.48 \pm 13.81$ & $193.82 \pm 15.19^{* *}$ & $181.62 \pm 21.67$ & $143.14 \pm 9.01$ & $165.31 \pm 13.39$ & $161.89 \pm 8.70$ \\
\hline AP peak (mV) & $67.00 \pm 4.47$ & $66.38 \pm 3.26$ & $68.71 \pm 2.37$ & $65.76 \pm 3.53$ & $68.40 \pm 2.66$ & $70.61 \pm 2.22$ & $67.19 \pm 2.47$ & $73.40 \pm 2.23$ \\
\hline fAHP (mV) & $-3.01 \pm 0.40$ & $-2.48 \pm 0.35$ & $-3.33 \pm 0.42$ & $-3.72 \pm 0.47$ & $-4.10 \pm 0.52$ & $-3.69 \pm 0.48$ & $-2.01 \pm 0.30$ & $-3.56 \pm 0.42^{*}$ \\
\hline $\mathrm{mAHP}(\mathrm{mV})$ & $-11.12 \pm 0.68$ & $-9.93 \pm 0.69$ & $-11.91 \pm 0.54$ & $-10.51 \pm 0.44$ & $-11.54 \pm 0.86$ & $-10.37 \pm 1.32$ & $-9.39 \pm 0.63$ & $-11.47 \pm 0.48$ \\
\hline
\end{tabular}

${ }^{a_{E}}$ Electrophysiological properties of GFP ${ }^{+}$and GFP ${ }^{-}$pyramidal cells from Paired and Unpaired mice across conditioning sessions. Data are mean \pm SEM. Liquid junction potential was $-13.7 \mathrm{mV}$ and was not adjusted for. Spike characteristics were determined from a single action potential (AP). When a doublet was elicited, the second spike was analyzed. Input resistance Ri was calculated from the slope of the $I-V$ curve measured in response to 4 pA current steps ranging from -60 to $40 \mathrm{pA}$. Spike threshold was measured using the third differential with Mini Analysis software. The AP peak was calculated as the difference between the AP peak and AP threshold. Half-width was measured as the AP width at half-maximal spike. Postspike fast and medium afterhyperpolarizations (fAHPs and mAHPs) were measured $\sim 3$ and $\sim 40$ ms following the AP threshold, respectively. Sidak post hoc tests between GFP ${ }^{+}$and GFP ${ }^{-}$are indicated.

${ }^{*} p<0.05$. ${ }^{* *} p<0.01$.

Slices were mounted on Superfrost Plus slides (catalog \#UY-48512-00, Cole-Parmer), air-dried, and coverslipped with PermaFluor (catalog \#TA-030-FM; Thermo Fisher Scientific). Fluorescence images of mCherry staining (see Fig. $7 B$ ) from both left and right hemispheres of the ACC of 2-4 coronal sections per animal, corresponding approximately to bregma 1.2 (Paxinos and Franklin, 2001), were captured using QI click camera (Qimaging) attached to a Bx53 microscope (Olympus). Fos-tTA mice not expressing mCherry $(n=2)$ were excluded from the study.

\section{In vivo $2 P$ imaging (Experiment 1 )}

Habituation and imaging sessions. Imaging sessions took place on headfixed, awake mice that were able to freely run on a polystyrene cylinder (see Fig. $3 C$ ). For $\sim 1$ week before the first imaging session, mice were habituated to being restrained by being head-fixed regularly for progressively increasing durations. Following habituation, the brain surface under the microprism was assessed and 2 or 3 areas of interest were defined. In each area of interest, $z$ stacks in both the red and green channels were recorded simultaneously at an excitation wavelength of $970 \mathrm{~nm}$ (power at the objective: $70-130 \mathrm{~mW}$; pixel dwell time: $\sim 3.9 \mathrm{~ns}$ ) from the pial surface to a depth of $\sim 300 \mu \mathrm{m}$. Each slice of the stack was an average of two $660.14 \times 660.14 \mu \mathrm{m}$ images (corresponding to $512 \times 512$ pixels; pixel size: $1.2695 \times 1.2695 \mu \mathrm{m})$. Images were captured in predefined areas of interest using a multiphoton microscope (Scientifica) with a $16 \times$ water-immersion objective (CFI LWD Plan Fluorite Physiology objective, NA 0.8, WD 3 mm; Nikon) and a Chameleon Vision-S Ti:Sapphire laser with dispersion precompensation (Chameleon, Coherent). The software used for recording was ScanImage r3.8 (Pologruto et al., 2003).

Imaging sessions took place $75 \mathrm{~min}$ following initiation of the $1 \mathrm{st}, 5$ th, and 11th conditioning session as well as the cue exposure test (see Fig. $3 C)$. Another two imaging sessions took place directly from the home cage (2-3 d before conditioning and 5-8 d after the cue exposure test). Imaging sessions typically lasted $40 \mathrm{~min}$ to an hour. Of note, GFP expression observed during imaging is unlikely to be caused by previous behavioral sessions as imaging took place exclusively following AM sessions, $\sim 18 \mathrm{~h}$ from the previous PM session where GFP expression returns to baseline levels (see Fig. 2A). Due to poor imaging quality on one or several imaging sessions, 3 mice (1 Unpaired, 2 Paired) were excluded from image analysis.

\section{Analysis}

Image analysis. Initial image processing took place in FIJI Image (Schindelin et al., 2012). tdTomato images within a stack were aligned to each other on $x$ and $y$ axes with MultiStackReg (Thévenaz et al., 1998). The resulting transformation was then applied to the GFP image stack. Stacks were aligned between sessions using the Landmark Correspondence plugin (Stephan Saalfeld, HHMI Janelia Research Campus). A volume within layers II/III common to all sessions was identified and selected. All images in the selected stacks were despeckled, and an FFT bandpass filter (upper threshold 40 pixels, lower threshold 5 pixels) was applied. Local maxima (noise tolerance: 30 pixels) were identified and the signal within a disk around the maxima (12 pixel diameter [15.234 $\mu \mathrm{m}]$ for GFP signal and 16 pixels diameter [ $20.312 \mu \mathrm{m}$ ] for tdTomato signal) was compared with the "noise" surrounding it (2.5390- $\mu \mathrm{m}$-thick band, $1.2695 \mu \mathrm{m}$ away from the disk). A cell was considered $\mathrm{GFP}^{+}$or tdTomato ${ }^{+}$(as appropriate) if "signal" $>$ "noise" + 2.3 SD (noise) for at least two consecutive slices in the stack (see Fig. 3B). Positive cells were recorded in an empty 3D matrix the size of the stack, and later the $x, y, z$ coordinates of each cell were extracted from the matrix using 3D object counter (Bolte and Cordelières, 2006).

A custom MATLAB (2016a, MathWorks) script defined whether each cell was a putative interneuron or pyramidal cell according to whether tdTomato signal was detected in a cell for a majority of recorded sessions. Repeatedly activated neurons were then identified by sorting cells according to their expression in all recording sessions. For each session, a cell's $x, y, z$ coordinates were compared with those obtained from previous sessions. If the $x, y$, and $z$ coordinates fell within a 20 pixel interval $(25.390 \mu \mathrm{m})$ of existing coordinates, it would be considered the same cell. If several existing coordinates fulfilled this condition, the cell was assigned to the closest set of coordinates on the $x, y$ plane as defined by Euclidean distance. If no coordinates fulfilled this condition, the cell was considered newly activated. To account for interindividual difference in cell density, GFP expression as well as any possible damages cause by microprism implantation to the tissue, all variables relating to $\mathrm{GFP}^{+}$ quantification were normalized to the average number of $\mathrm{GFP}^{+}$cells detected in home cage sessions, which was considered our baseline activation level (see Fig. 3D).

\section{Experimental design and statistical analysis}

In the main text, we report all main and interaction effects that are key to data interpretation. All data were analyzed using Prism (RRID: SCR_002798, GraphPad Software) and SPSS (IBM, version 23.0, 2015). Group data are presented as mean \pm SEM.

Fos-GFP time course expression data. All sample sizes are detailed in the Figure 2 legend. The goal of this experiment was to measure the number of activated neurons expressing GFP in the $\mathrm{dmPFC}$ at different time points following novel context exposure (see Fig. 2A). To this end, FosGFP mice were randomly assigned the $0,1.5,8$, and 18 h groups. Thus, depending on condition, Fos-GFP mice in the 1.5, 8, and $18 \mathrm{~h}$ condition were initially exposed to a novel context for $25 \mathrm{~min}$ and then remained in their home cages for an additional $65 \mathrm{~min}, 7 \mathrm{~h} 35 \mathrm{~min}$, and $17 \mathrm{~h} 35 \mathrm{~min}$, respectively, and subsequently were deeply anesthetized and transcardially perfused with $4 \%$ PFA. Fos-GFP mice in the $0 \mathrm{~h}$ condition were transcardially perfused without being exposed to the novel context. Following perfusions, we removed their brains and processed them for GFP immunohistochemistry. GFP expression 
data were analyzed using a one-way ANOVA in Prism, followed by post hoc testing (Sidak correction).

Experiment 1: behavior and in vivo $2 P$ imaging. All sample sizes are detailed in the Figures 1, 3, and 4 legends. The broad aim of this experiment was to characterize Fos-GFP expression patterns in activated pyramidal cells (Fos-GFP ${ }^{+} /$tdTomato $^{-}$cells) and interneurons (Fos-GFP ${ }^{+}$/ tdTomato ${ }^{+}$cells) as a function of appetitive conditioning and memory recall (see Figs. 3, 4). To this end, FGGT mice were randomly divided into Paired (conditioned) and Unpaired (control) groups, then underwent behavioral training (see Fig. 1) and 2P imaging following S1, S5, and S11 of conditioning and a test for Recall (see Figs. 3C, 4).

First, to determine whether Paired FGGT mice acquired a CS-US association, we measured head entries into the sucrose delivery magazine during the CS (cue-on) and ITI (no cue) periods (see Fig. $1 A, B$ ). These data were analyzed using a three-way mixed ANOVA using the factors Cue (cue-on, no cue), Session, and Group (Paired, Unpaired; Fig. 1B). Additionally, for the Paired group only, we calculated selectivity indices (CS entries - ITI entries)/Total entries) and analyzed them using oneway repeated-measures ANOVA in SPSS (see Fig. 1D). A proportion of mice from these groups were randomly selected to undergo cue-evoked food seeking in Recall (see Fig. 1C). These data were analyzed using a two-way mixed ANOVA in Prism using the factors Cue and Group. Following the two-way mixed ANOVA, a further post hoc test was performed (Sidak correction) since an interaction was observed $(p<0.05)$.

We performed $2 \mathrm{P}$ imaging of $\mathrm{GFP}^{+}$pyramidal cells and interneurons during baseline, conditioning, and Recall. Pyramidal cells and interneurons are affected differently by glutamatergic signaling (Riebe et al., 2016), suggesting distinct Fos induction thresholds; as such, they were analyzed separately. Due to poor imaging quality on one or several imaging sessions, 3 mice (1 Unpaired, 2 Paired) were excluded from image analysis. To determine whether baseline $\mathrm{GFP}^{+}$counts for pyramidal cells and interneurons were similar between groups, we examined the number of $\mathrm{GFP}^{+}$neurons per $\mathrm{mm}^{3}$ with a two-way mixed ANOVA using the factors Group and Session in Prism (see Fig. 3D). Subsequent GFP ${ }^{+}$ counts were normalized to this baseline. To examine whether the number of $\mathrm{GFP}^{+}$neurons were modulated as a function of conditioning, we performed two-way mixed ANOVAs using the factors Group $\times$ Session in Prism (see Fig. 4A). We also examined whether conditioning modulated the number of repeatedly activated neurons according to their S1 activation history $\left(\mathrm{S}^{+} \mid \mathrm{S}^{+}{ }^{+} \mathrm{S} 11^{+}, \mathrm{S}^{-}{ }^{-} \mathrm{S}^{+}{ }^{+} \mathrm{S} 11^{+}\right)$, and performed two-way mixed ANOVAs using the factors Activation History and Group in Prism (see Fig. 4C). Following two-way mixed ANOVAs, further post hoc tests were performed (Sidak correction) if an interaction was observed $(p<0.05)$. The results from the Recall test were analyzed for differences in Fos-GFP ${ }^{+}$neurons using $t$ tests in Prism (see Fig. 4E). Additionally, to determine whether conditioning modulated the number of recall-activated $\mathrm{GFP}^{+}$neurons with a repeated activation history during conditioning according to their $\mathrm{S} 1$ activation $\left(\mathrm{S}^{+} \mid \mathrm{S} 5^{+} \mathrm{S}_{1} 1^{+} \mathrm{R}^{+}\right.$or $\left.\mathrm{S} 1^{-} \mid \mathrm{S}^{+}{ }^{+} \mathrm{S} 11^{+} \mathrm{R}^{+}\right)$, we performed two-way mixed ANOVAs using the factors Activation history and Group (see Fig. $4 F$ ). Further post hoc tests were performed (Sidak correction) if an interaction was observed $(p<$ 0.05 ). Also, to better characterize the proportion of neurons recruited in S1 and Recall according to their subsequent (see Fig. $4 D$ ) and previous reactivation patterns (see Fig. $4 G$ ), as well as characterizing the reactivation of repeatedly activated neurons $\left(\mathrm{S}^{+} \mid \mathrm{S} 5{ }^{+} \mathrm{S} 11^{+}\right)$in Recall (see Fig. $4 H$ ), $\chi^{2}$ tests were performed on pooled neurons (Activation history $X$ Group) in SPSS and further post hoc procedures (Bonferroni correction) (Beasley and Schumacker, 1995) performed if a significant interaction was observed $(p<0.05)$.

Experiment 2: ex vivo electrophysiology. All sample sizes are detailed in the legends of Figures 5, 6, and 7. The purpose of the electrophysiological experiments was to reveal the intrinsic, synaptic, and connectivity properties of recently activated $\mathrm{GFP}^{+}$neurons and their surrounding $\mathrm{GFP}^{-}$ neurons following the early (S1) and late (S11) phases of conditioning. Similar to Experiment 1, Fos-GFP and TetTag H2B-GFP mice were randomly assigned into Paired (conditioned) and Unpaired (control) groups and underwent identical behavioral training procedures. At $1.5 \mathrm{~h}$ following training session onset at S1 or S11 (Fos-GFP mice) and 3-7 d following S1 (TetTag H2B-GFP mice), their brains were removed for
Table 2. Passive and active membrane properties from TetTag H2B-GFP mice 3-7 d following $\mathrm{S1}^{a}$

\begin{tabular}{|c|c|c|c|c|}
\hline & \multicolumn{4}{|l|}{ H2B-GFP } \\
\hline & \multicolumn{2}{|l|}{ Unpaired } & \multicolumn{2}{|l|}{ Paired } \\
\hline & $\mathrm{GFP}^{-}$ & $\mathrm{GFP}^{+}$ & $\mathrm{GFP}^{-}$ & $\mathrm{GFP}^{+}$ \\
\hline Resting $V_{\mathrm{m}}(\mathrm{mV})$ & $-66.42 \pm 0.67$ & $-68.19 \pm 1.00$ & $-66.37 \pm 0.79$ & $-66.63 \pm 0.56$ \\
\hline Rheobase (pA) & $76.92 \pm 3.63$ & $76.57 \pm 4.47$ & $77.00 \pm 6.52$ & $67.38 \pm 4.43$ \\
\hline $\mathrm{R}_{\mathrm{i}}(\mathrm{M} \Omega)$ & $177.11 \pm 9.04$ & $200.33 \pm 7.57$ & $195.55 \pm 9.74$ & $216.52 \pm 9.22$ \\
\hline AP peak (mV) & $63.38 \pm 2.27$ & $58.62 \pm 2.55$ & $62.09 \pm 2.24$ & $61.44 \pm 3.19$ \\
\hline AP half-width (ms) & $1.36 \pm 0.05$ & $1.30 \pm 0.05$ & $1.42 \pm 0.04$ & $1.34 \pm 0.05$ \\
\hline Threshold (mV) & $-34.62 \pm 0.64$ & $-33.57 \pm 0.57$ & $-34.64 \pm 0.54$ & $-34.70 \pm 0.71$ \\
\hline fAHP (mV) & $-4.27 \pm 0.43$ & $-3.87 \pm 0.48$ & $-3.71 \pm 0.44$ & $-4.36 \pm 0.50$ \\
\hline $\mathrm{mAHP}(\mathrm{mV})$ & $-12.62 \pm 0.85$ & $-11.00 \pm 0.78$ & $-12.75 \pm 1.07$ & $-11.41 \pm 2.22$ \\
\hline
\end{tabular}

${ }^{a_{E}}$ Electrophysiological properties of H2B-GFP ${ }^{+}$and H2B-GFP ${ }^{-}$neurons from Paired and Unpaired mice. Data are mean \pm SEM

electrophysiological analyses. Spike counts (see Fig. 5A-C) were analyzed separately at S1 and S11 (unless specified otherwise in text), using threeway mixed ANOVAs, including the factors Group, GFP $\left(\mathrm{GFP}^{+}, \mathrm{GFP}^{-}\right)$, and a repeated-measures factor of Current (12 pA increments) in SPSS. Other intrinsic active and passive membrane properties (Tables 1,2) and synaptic properties (AMPAR/NMAR ratio, sEPSC amplitude and frequency; see Fig. $6 A-C$ ) were analyzed using two-way ANOVAs with Group and GFP as factors, with S1 and S11 analyzed separately in Prism. PPRs were analyzed using a three-way mixed ANOVA, including the factors Group, GFP, and interstimulus interval (20, 40, 60, 80, 100, 150, and $200 \mathrm{~ms}$ ) in SPSS (see Fig. 6D). Connectivity (see Fig. 7) was determined using Fisher's Exact test on $2 \times 2$ frequency matrices (column: Paired, Unpaired; row: Connected, Unconnected) separately for each pair type $(+/+,+/-,-/+)$ and session condition $(S 1, S 11)$ in SPSS. Average connectivity was calculated as follows: (sum of all connected pairs/total connections tested) $\times 100$. Outliers were detected using GRUBBS detection test $(\alpha=0.05)$ in Prism and excluded from analyses. Post hoc tests were conducted using a Sidak's multiple-comparisons test, if significant interactions were observed.

Experiment 3: DREADD manipulation of S1- and NC-tagged neurons. All sample sizes are detailed in the Figure 8 legend. The goal of this experiment was to examine the behavioral effects of chemogenetically, repeatedly increasing the excitability of S1-tagged (activated) neurons on appetitive conditioning. The experimental timeline is shown in Figure 8A. To this end, Fos- $t T A$ mice and their negative, WT littermates were injected with $\mathrm{AAV}_{2^{-}}$ $\mathrm{TRE}_{\text {tight }}$-hM3Dq-mCherry in the dmPFC for two separate experiments, $\mathrm{S} 1$ tag and novel context or NC tag (to rule out effects of general tagging). Fos-tTA and WT mice were randomly assigned to the S1 and NC tag conditions. Data from these conditions were analyzed separately.

To determine whether repeated hM3Dq activation of S1- and NCtagged neurons via clozapine modulated conditioning, head entries (see Fig. $8 D, G)$ were analyzed using three-way mixed ANOVAs using the factors Genotype (Fos-tTA, WT), Cue, and Session in SPSS, and the Selectivity Index data (see Fig. $8 C, F$ ) were analyzed using two-way mixed ANOVAs using the factors Genotype and Session in Prism. Following two-way mixed ANOVAs, further post hoc tests were performed (Sidak correction) if an interaction was observed $(p<0.05)$. To test the effects of repeated hM3Dq activation on cue-evoked food-seeking during Recall, head entries were analyzed using two-way mixed ANOVAs using the factors Genotype and Cue in Prism (see Fig. 8E,H).

\section{Results}

\section{Appetitive conditioning shapes CS-selective approach} behaviors in FGGT mice

Microprism-implanted Fos-GFP $\times$ GAD-tdTomato (FGGT) mice were trained on a simple appetitive conditioning task (Fig. $1 A$ ) under freely moving conditions. Across the 12 acquisition sessions ( 1 or 2 sessions per day), mice assigned to the Paired group received repeated trials during which an auditory cue (CS) was paired with liquid sucrose delivery (US). Mice in the Un- 
A

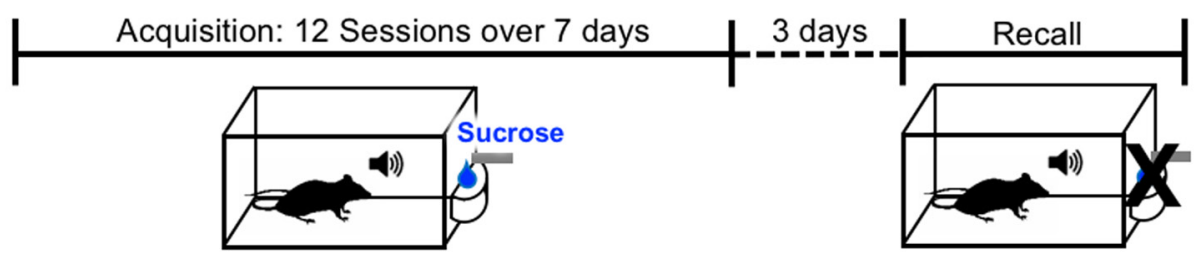

B

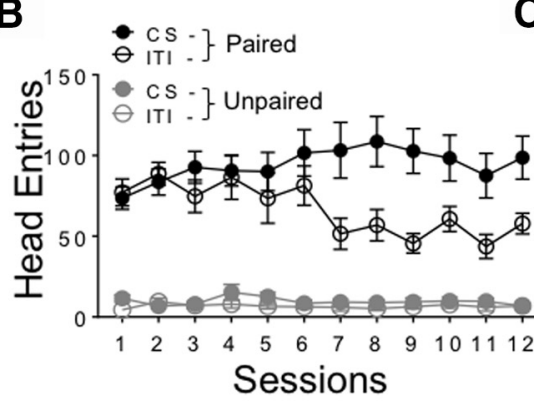

c

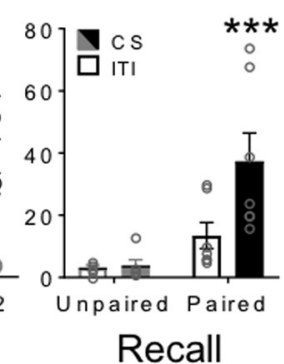

D

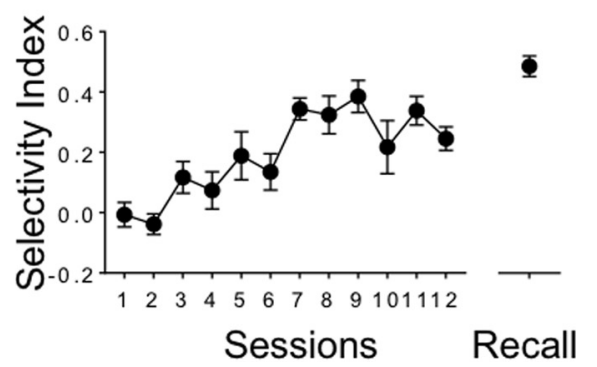

Figure 1. Experimental timeline and conditioned approach performance in FGGT mice. $\boldsymbol{A}$, Timeline of conditioning and imaging sessions ( 1 or 2 sessions per day). $\boldsymbol{B}$, Head entries into the magazine during the CS (cue-on) compared with ITI (no cue) periods as a function of conditioning session. C, Approach responses during CS and ITI trials during the test for recall by Paired and Unpaired groups. $D$, Selectivity Index (CS-ITI/total number head entries) of Paired mice during Acquisition and Recall. Data are mean \pm SEM. ${ }^{* * *} p<0.001$. Paired (P), $n=12 ;$ Unpaired (UP), $n=$ 10. Paired (P), $n=6$; Unpaired (UP), $n=6$ for Recall.

paired (control) group received an equal number of CS presentations in the conditioning chamber, but received sucrose in their home cage only. As such, this group controlled for factors, such as the effects of handling, and exposure to the conditioning chamber, CS and US. Three days following the last acquisition session, mice were tested on a CS-US memory recall test conducted under extinction conditions (Fig. 1A). Similar to our recent study (Ziminski et al., 2017), initial analysis of acquisition and recall test performance revealed significant interaction effects of Cue $\times$ Session $\times$ Group (Fig. $1 B ; F_{(11,220)}=5.94, p<0.001$ ) and Group $\times$ Cue (Fig. $1 C ; F_{(1,11)}=15.46, p<0.01$ ), respectively, indicating cue-selective approach responding or food seeking during the CS versus the ITI (no cue) periods. We further assessed conditioning performance by calculating a Selectivity Index (Fig. 1D) by subtracting ITI from CS-trial head entry counts and normalizing to total head entries. During acquisition, there was a significant effect of Session $\left(F_{(11,121)}=9.50, p<0.001\right)$ in the Paired group, indicating that Paired mice came to selectively respond to the CS as a function of training.

\section{The time course of Fos-GFP expression}

In Fos-GFP mice, a transgene containing a $c$-fos promoter drives expression of a gene encoding a fusion protein of Fos and GFP, Fos-GFP, in behaviorally activated neurons (Barth et al., 2004; Koya et al., 2012). We characterized the time course of GFP expression in the $\mathrm{dmPFC}$ following $0,1.5,8$, and $18 \mathrm{~h}$ exposure to a novel context (locomotor activity chamber). A one-way ANOVA followed by post hoc testing revealed that GFP expression was significantly elevated at 1.5 compared with 0,8 , and $18 \mathrm{~h}$ and that there were no differences between the 0,8 , and 18 h groups $\left(F_{(3,15)}=19.72, p<0.001\right.$; Fig. $\left.2 A\right)$. Thus, GFP expression peaked at $1.5 \mathrm{~h}$ and returned to baseline levels at 8 and $18 \mathrm{~h}$. These and other findings (Barth et al., 2004; Cifani et al., 2012) further validate the use of Fos-GFP as a recent, but not a remote marker, of neuronal activity. Hence, we performed our in vivo imaging and ex vivo electrophysiological characterization of Fos-GFP-expressing neurons following $\sim 1.5 \mathrm{~h}$ from the initiation of behavioral testing.
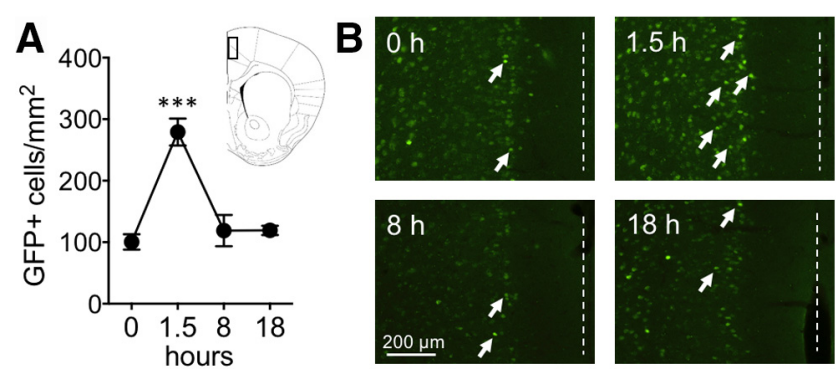

Figure 2. dmPFC Fos-GFP expression peaks at $1.5 \mathrm{~h}$ and returns to baseline at 8 and $18 \mathrm{~h} . \boldsymbol{A}$, Time course of GFP expression and approximate location of cell counts. Data are from naive Fos-GFP mice that were perfused at $0,1.5,8$, and $18 \mathrm{~h}$ following exposure to a novel context. $\boldsymbol{B}$, Representative images of GFP labeling from the dmPFC. White arrows indicate Fos-GFP ${ }^{+}$cells. Dashed white line indicates position of midline. Data are mean \pm SEM. ${ }^{* *} p<0.001(n=5$, 5,5 , and 4 mice for $0,1.5,8$, and $18 \mathrm{~h}$ groups, respectively).

As the CS-US association is established, a stable neuronal ensemble is recruited from a wider pool of neurons activated in the initial conditioning session

We used $2 \mathrm{P}$ imaging in microprism-implanted FGGT mice to characterize activation among pyramidal cells (tdTomato ${ }^{-}$) and interneurons $\left(\right.$ tdTomato $^{+}$) in layers II/III of the dmPFC (Fig. 3A-C). To assess baseline GFP expression, we first examined the number of $\mathrm{GFP}^{+}$pyramidal cells and interneurons per $\mathrm{mm}^{3}$ in mice that have been in the home cage (HC) for at least $24 \mathrm{~h}$. Imaging sessions were conducted both before ( $\mathrm{HC1}$ ) and after (HC2) mice underwent behavioral training. We observed no significant interaction effect of Group $\times$ Session for pyramidal cells $\left(F_{(1,17)}=0.02, p=0.89\right)$ and interneurons $\left(F_{(1,17)}=1.84, p=0.19\right.$; Fig. $\left.3 D\right)$. Thus, behavioral training did not modulate baseline GFP expression for both cell types. In further analyses, to account for interindividual differences in cellular density and GFP expression, the number of $\mathrm{HC} 1$ and $\mathrm{HC} 2$ $\mathrm{GFP}^{+}$pyramidal cells and interneurons were averaged for each mouse and used to normalize subsequent $\mathrm{GFP}^{+}$cell counts.

Approximately 80-90 min following the initiation of the 1st, 5th, and 11th acquisition sessions and the recall session, we used 
A
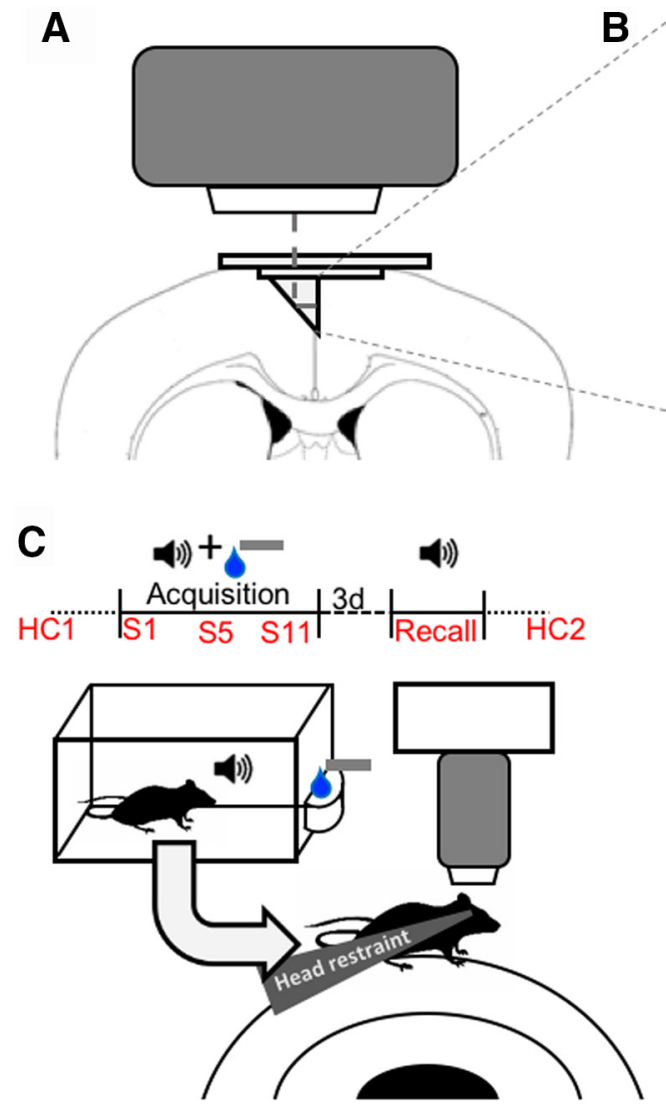

B

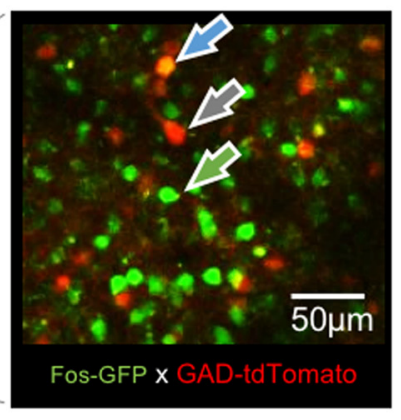

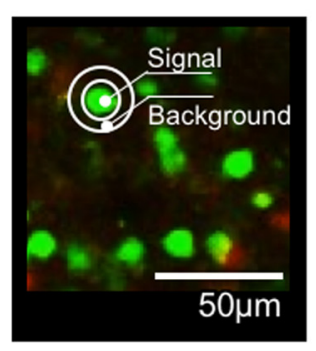

:

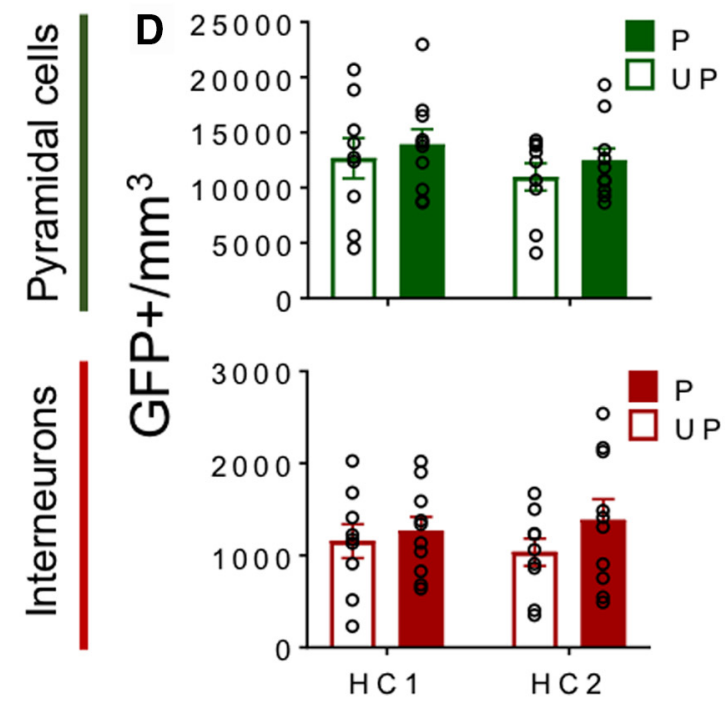

Figure 3. Experimental timeline, methods of $2 P$ imaging, and baseline Fos-GFP expression. GFP expression was longitudinally monitored in pyramidal cells and interneurons. $A$, Microprism placement for dmPFC imaging. $\boldsymbol{B}$, Representative in vivo 2 P image of dmPFC from Fos-GFP $\times$ GAD-tdTomato (FGGT) mice. Green arrow indicates GFP. Gray arrow indicates tdTomato. Blue arrow indicates GFP ${ }^{+}$tdTomato. GFP ${ }^{+}$neurons were selected by comparing Signal intensity with Background. C, Imaging timeline and schematic representation of imaging session in head-fixed mice following behavioral training under freely moving conditions (S1, S5, S11, and Recall) or from home cage (HC1, HC2). D, Number of GFP ${ }^{+}$pyramidal cells (green) and interneurons (red) per mm ${ }^{3}$ in imaging sessions taking place directly from home cage both before (HC1) and after (HC2) behavioral training. Data are mean \pm SEM. Paired (P), $n=10 ;$ Unpaired (UP), $n=9$.

$2 \mathrm{P}$ imaging to characterize neuronal activation patterns among pyramidal cells and interneurons in the dmPFC (Fig. $3 A-C$ ). Hence, the observed GFP expression reflects neuronal activity of the dmPFC during the behavioral sessions under freely moving conditions. We first assessed the overall number of strongly activated, $\mathrm{GFP}^{+}$pyramidal cells and tdTomato ${ }^{+}$interneurons on the 1st (S1), 5th (S5), and 11th (S11) conditioning sessions (Fig. $4 A$ ), which occurred 2-3 d apart from each other (since 1 or 2 sessions are conducted per day). No significant interactions of Group $\times$ Session were observed in pyramidal cells $\left(F_{(2,34)}=0.20\right.$, $p=0.82)$ or interneurons $\left(F_{(2,34)}=0.06, p=0.95\right)$, indicating that the total number of activated neurons across acquisition sessions did not fluctuate as a function of conditioning for either cell type in the dmPFC.

Repeated, persistent activation of the same set of neurons in the nucleus accumbens underlies conditioning using a drug reward, suggesting that such neurons with repeated activation history encode associative information (Mattson et al., 2008). Moreover, activity in the motor cortex early in learning of a simple motor task is a critical determinant for ensemble consolidation (Cao et al., 2015). Thus, we investigated whether appetitive Pavlovian conditioning preferentially recruits a learning-relevant, repeatedly activated ensemble from a wider pool of candidate neurons activated at S1, before the development of a robust CSevoked food seeking response. To this end, Unpaired and Paired groups were assessed and compared for the number of $\mathrm{GFP}^{+}$ neurons in two distinct Activation History categories: neurons that were persistently activated $(+)$ in $S 5$ and S11, following activation in $\mathrm{S} 1\left(\mathrm{~S}^{+} \mid \mathrm{S}^{+} \mathrm{S}^{+} 1^{+}\right)$, or neurons activated in $\mathrm{S} 5$ and $\mathrm{S} 11$, but that were not activated on the initial conditioning session $\left(\mathrm{S}^{-} \mid \mathrm{S}^{+} \mathrm{S} 1^{+}\right.$; Fig. $\left.4 \mathrm{~B}, \mathrm{C}\right)$. In pyramidal cells, there was a significant interaction effect of Activation History $\times$ Group $\left(F_{(1,17)}=5.97, p<0.05\right)$, followed by a significant main effect of Activation History $\left(F_{(1,17)}=61.75, p<0.001\right)$, but not Group $\left(F_{(1,17)}=1.17, p=0.29\right)$. Conversely, there was no significant interaction effect of Activation History $\times$ Group in interneurons $\left(F_{(1,17)}=0.17, p=0.68\right)$, but a significant main effect of Activation History $\left(F_{(1,17)}=8.10, p<0.05\right)$, but not $\operatorname{Group}\left(F_{(1,17)}=\right.$ $1.10, p=0.31)$. Hence, conditioning recruited a repeatedly activated ensemble from a pool of pyramidal cells activated in S1.

Having established the relevance of S1 activation to the development of a neuronal ensemble as a function of conditioning, we wanted to better characterize neurons recruited in $\mathrm{S} 1$ and in particular, their subsequent reactivation patterns (Fig. 4D). To this end, we assessed the proportion of S1-activated neurons that were reactivated in $\mathrm{S} 5$ only $\left(\mathrm{S}^{+} \mid \mathrm{S} 5^{+} \mathrm{S} 11^{-}\right), \mathrm{S} 11$ only $\left(\mathrm{S} 1^{+} \mid \mathrm{S} 5^{-} \mathrm{S} 11^{+}\right)$, 


\section{- Acquisition $+3 \mathrm{~d}-\left.\right|_{\text {Recall }}$}

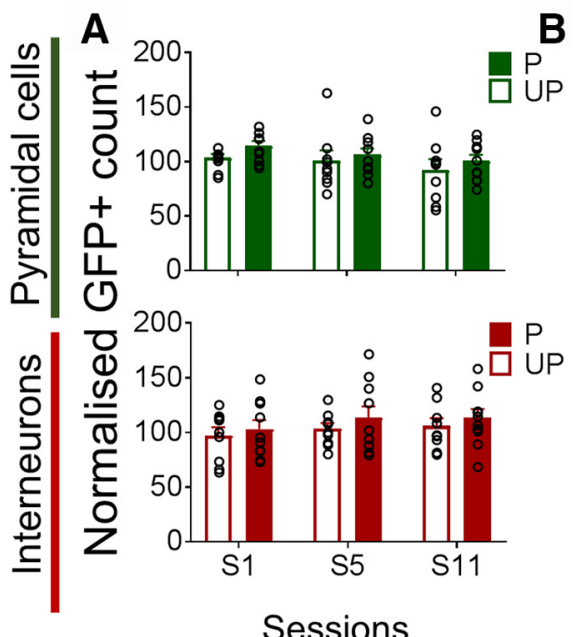

\section{Sessions}

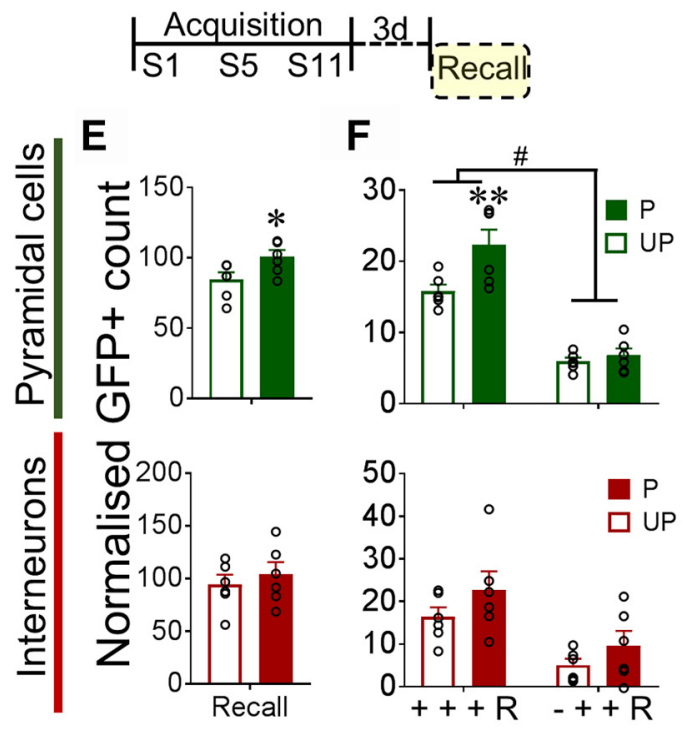

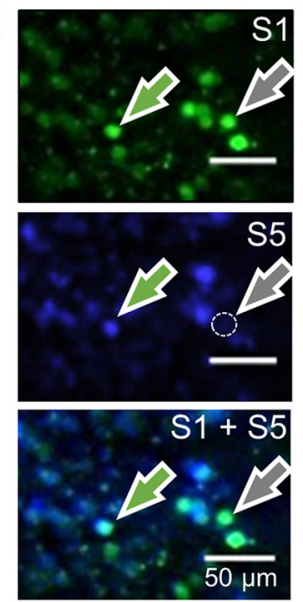
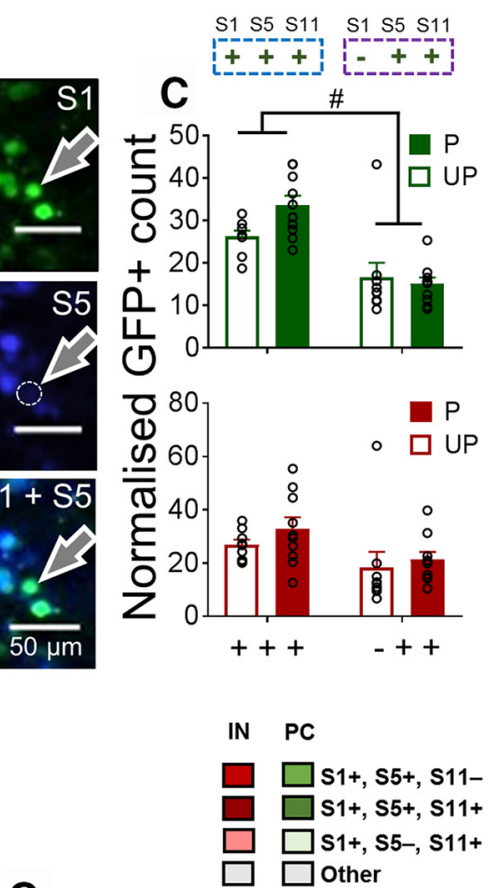

G

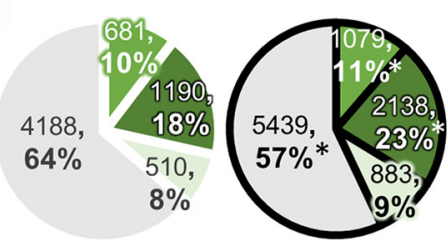

\section{Recall GFP+}

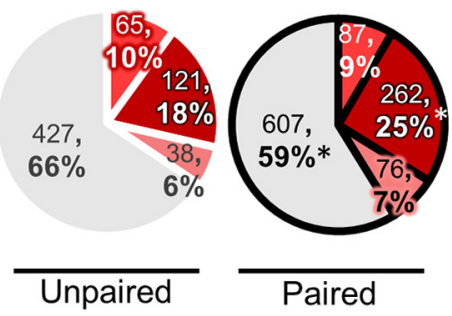

IN PC

$\square \square \mathrm{s} 1+, \mathrm{s} 5+, \mathrm{s} 11-$

$\square \mathrm{s} 1+, \mathrm{s} 5+, \mathrm{s} 11+$

$\square \square \mathrm{s} 1+, \mathrm{s} 5-, \mathrm{s} 11+$

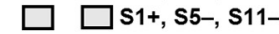

D
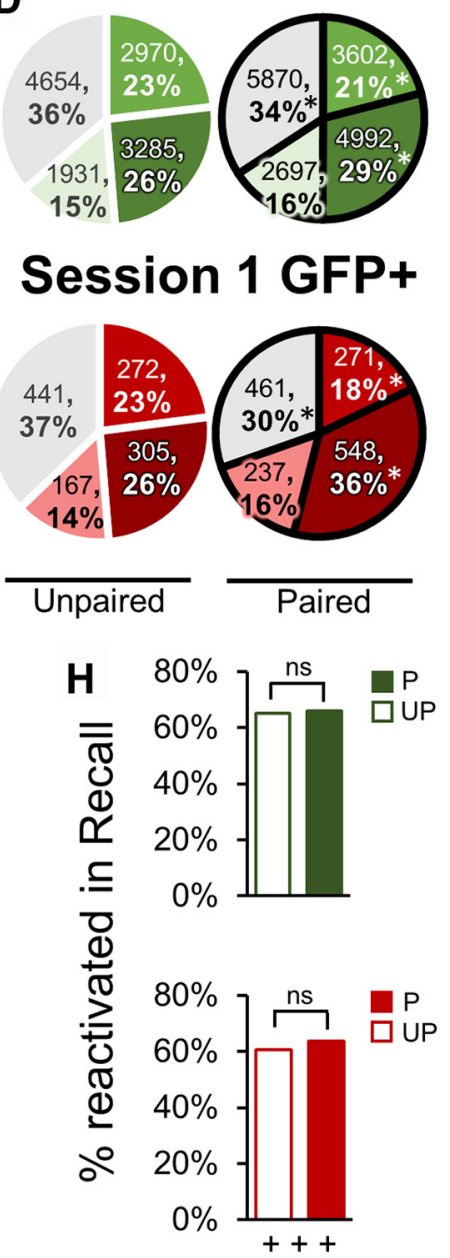

Figure 4. Conditioning and memory recall recruit a stable pyramidal cell (PC) ensemble from the initial acquisition session. $A_{\text {, Normalized GFP }}{ }^{+}$counts of PCs (green) and interneurons (IN) (red) during acquisition sessions. B, Representative image of longitudinal GFP imaging (S1 and S5). Green arrow indicates $S 1^{+} \mid S 5^{+}$neurons. Gray arrow indicates $S 1^{+} \mid S 5^{-}$neurons. $C$, Normalized $\mathrm{GFP}^{+}$counts of PCs and INs with an $\mathrm{S1}(+++)$ or no S1 $(-++)$ activation history. D, Distribution of GFP ${ }^{+} \mathrm{PCs}$ and INs activated during S1 classified according to their subsequent reactivation patterns $\left(\mathrm{S}^{+}\left|\mathrm{S} 5^{+}, \mathrm{S} 11^{+} ; \mathrm{S1}^{+}\right| \mathrm{S} 5^{+}, \mathrm{S} 11^{-} ; \mathrm{S} 1^{+}\left|\mathrm{S} 5^{-}, \mathrm{S} 11^{+} ; \mathrm{S1}^{+}\right| \mathrm{S} 5^{-}, \mathrm{S} 11^{-}\right)$for Paired and Unpaired mice. $\boldsymbol{E}$, Normalized $\mathrm{GFP}^{+}$counts of PCS and INs following the test for memory recall. $F$, Normalized GFP ${ }^{+}$counts of $\mathrm{PCS}$ and INs recruited during the test for recall that had been persistently activated during training, as a function of their $\mathrm{S} 1$ activation history $(+++R$ or -++ R). G, Distribution of GFP ${ }^{+} \mathrm{PCS}$ and INs activated during the test for recall, classified according to their activation patterns from S1 onwards in Paired and Unpaired mice. Other, Neurons recruited during recall that did not demonstrate activation histories of interest (e.g., $\left.\mathrm{S} 1^{-} \mid S 5^{-}, \mathrm{S} 11^{+}\right)$. $\boldsymbol{H}$, Proportion of $\mathrm{S} 1^{+} \mid S 5^{+} \mathrm{S} 11^{+} \mathrm{PCs}$ and INs that were reactivated in Recall for Paired and Unpaired mice. Data on bar graphs are mean \pm SEM. Normalization of GFP ${ }^{+}$counts was performed using the average number of GFP ${ }^{+}$neurons in $\mathrm{HC}_{\text {(number of GFP }}{ }^{+}$cells/average number of GFP ${ }^{+}$in HC) $\times 100$ ). Interaction effect: ${ }^{\#} p<0.05$. Post hoc analysis: ${ }^{* *} p<0.01$. Paired (P), $n=10$; Unpaired (UP), $n=9$ for acquisition; Paired (P), $n=6$; Unpaired (UP), $n=6$ for Recall.

or $\mathrm{S} 5$ and $\mathrm{S} 11\left(\mathrm{~S}^{+} \mid \mathrm{S}^{+} \mathrm{S}^{+} 1^{+}\right)$as well as neurons activated in $\mathrm{S} 1$ but not $\mathrm{S} 5$ and $\mathrm{S} 11\left(\mathrm{~S}^{+} \mid \mathrm{S} 5^{-} \mathrm{S} 11^{-}\right)$. During conditioning, there was a significant interaction of Activation History $\times$ Group for both pyramidal cells $\left(\chi_{(3)}^{2}=58.98, p<0.001\right)$ and interneurons $\left(\chi_{(3)}^{2}=41.63, p<0.001\right)$. Of note, there was a significantly higher proportion of $\mathrm{S}^{+} \mid \mathrm{S}^{+} \mathrm{S}_{1} 1^{+}$neurons reactivating in Paired mice compared with Unpaired mice $(p<0.05)$ for both pyramidal cells and interneurons. Furthermore, only 29\% of S1activated neurons were recruited into the persistently activated ensemble $\left(\mathrm{S} 1^{+} \mid \mathrm{S} 5^{+} \mathrm{S} 11^{+}\right)$.
We also characterized neuronal activation patterns of pyramidal cells and interneurons following the Recall test (Fig. 4E). We observed a significantly higher number of pyramidal cells recruited following Recall in Paired mice compared with Unpaired mice $\left(t_{(10)}=2.40, p<0.05\right)$. We did not observe a significant effect in interneurons $\left(t_{(10)}=0.67, p=0.52\right)$.

Next, we compared the number of $\mathrm{GFP}^{+}$neurons activated during the test for recall with a S1 ${ }^{+} \mid \mathrm{S}^{+} \mathrm{S}^{+} 1^{+}$or $\mathrm{S}^{-} \mid \mathrm{S}^{+}{ }^{+} \mathrm{S} 11^{+}$ activation history (Fig. $4 F$ ). In pyramidal cells, there was a significant interaction effect of Activation History $\times \operatorname{Group}\left(F_{(1,10)}=\right.$ 
7.65, $p<0.05)$, and main effects of Activation History $\left(F_{(1,10)}=\right.$ 155.3, $p<0.001)$ and Group $\left(F_{(1,10)}=5.90, p<0.05\right)$. Post hoc testing revealed a significant increase in the number of $\mathrm{S}^{+} \mid \mathrm{S}^{+}$ $\mathrm{S}_{11}{ }^{+}$neurons activated during Recall $\left(\mathrm{S}^{+} \mid \mathrm{S}^{+} \mathrm{S}^{+} 1^{+} \mathrm{R}^{+}\right)$in Paired mice compared with Unpaired mice $(p<0.01)$. There was no significant interaction of Activation History $\times$ Group in interneurons $\left(F_{(1,10)}=0.24, p=0.64\right)$, but a significant main effect of Activation History $\left(F_{(1,10)}=44.69, p<0.001\right)$, but not Group $\left(F_{(1,10)}=1.93, p=0.20\right)$. Thus, similar to the conditioning phase, memory recall recruited an ensemble that was persistently activated from a pool of pyramidal cells activated in S1.

We also assessed the proportion of Recall-activated neurons that had been repeatedly reactivated in Acquisition following activation in $\mathrm{S} 1\left(\mathrm{~S}^{+}\left|\mathrm{S}^{+}{ }^{+} \mathrm{S} 11^{-}, \mathrm{S}_{1}{ }^{+}\right| \mathrm{S}^{+}{ }^{+} \mathrm{S} 11^{+}\right.$, and $\mathrm{S}^{+} \mid \mathrm{S} 5^{-}$ $\mathrm{S}_{1}{ }^{+}$; Fig. $\left.4 G\right)$. There was a significant interaction of Activation History $\times$ Group for both pyramidal cells $\left(\chi_{(3)}^{2}=77.51 ; p<\right.$ $0.001)$ and interneurons $\left(\chi_{(3)}^{2}=13.54 ; p<0.001\right)$. Notably, there was a significantly higher proportion of Recall-activated pyramidal cells, and interneurons also activated in Acquisition S1, S5, and S1 1 in Paired mice compared with Unpaired mice $(p<0.05)$. There was also a higher proportion of pyramidal cells with a $\mathrm{S}^{+}$ $\mathrm{S}^{+}{ }^{+} \mathrm{S} 11^{-}$history, suggesting that $\mathrm{S} 1$ recruitment may be involved in conditioning-specific activation dynamics beyond the recruitment of a stable ensemble. Furthermore, only $23 \%$ of Recall-activated pyramidal cells exhibited a repeated activation history during conditioning $\left(\mathrm{S}^{+} \mid \mathrm{S}^{+} \mathrm{S}^{+} 1^{+}\right)$.

Of note, $65 \%$ (UP) to $66 \%(\mathrm{P})$ of pyramidal cells and $61 \%$ (UP) to $63 \%(\mathrm{P})$ of interneurons that were repeatedly activated in acquisition $\left(\mathrm{S}^{+} \mid \mathrm{S} 5^{+} \mathrm{S} 11^{+}\right)$were reactivated in Recall (Fig. $\left.4 H\right)$. There was no significant interaction of Group $\times$ Activation history for pyramidal cells $\chi_{(1)}^{2}=0.42, p=0.52$ ) or interneurons $\left.\chi_{(1)}^{2}=0.55, p=0.46\right)$, suggesting that conditioning does not modulate the likelihood of reactivation of persistently activated neurons in Recall. A point to consider here is that, while a similar proportion of persistently activated neurons are reactivated in Recall in both groups, this reflects a greater number of these persistently activated neurons in the Paired group compared with the Unpaired group following conditioning.

Together, we demonstrate that, during the establishment and recall of a CS-US association, a stable neuronal ensemble is recruited in the mPFC from a pool of pyramidal cells that were initially activated in S1, when the acquisition of robust CS-US representations is yet to occur. Thus, activation in early learning may be a factor in allocating neurons to a stable conditioning specific ensemble.

\section{Activation of a hyperexcitable pool of neurons following the initial conditioning session}

Having established activation at $\mathrm{S} 1$ as a potential factor that modulates recruitment of neurons into an ensemble, we next determined the physiological properties of pyramidal cells activated during the initial conditioning session, before the development of cue-selective food seeking. The regulation of $\mathrm{GFP}^{+} / \mathrm{GFP}^{-}$excitability is thought to improve the signal-to-noise ratio of activated ensemble neurons (Whitaker and Hope, 2018). Thus, we initially analyzed the excitability of $\mathrm{GFP}^{+}$and $\mathrm{GFP}^{-}$pyramidal cells in Paired and Unpaired Fos-GFP mice 90 min following initiation of $\mathrm{S} 1$ and observed significant alterations in firing capacity across groups (Fig. 5A; Group $\times$ Cell type $\times$ Current $F_{(12,600)}=6.38$, $p<0.001)$. Further analysis revealed a significant difference in excitability between $\mathrm{GFP}^{+}$and $\mathrm{GFP}^{-}$neurons in Paired (Cell type $\times$ Current, $\left.F_{(12,348)}=9.42, p<0.001\right)$, but not Unpaired mice (Fig. $\left.5 A ; F_{(12,252)}=0.69, p=0.76\right)$. We then examined the underlying intrinsic adaptations that may contribute to the increased firing capacity of $\mathrm{GFP}^{+}$neurons (Table 1 ). In Paired mice only, the input resistance $\left(\mathrm{R}_{\mathrm{i}}\right)$, as measured by shifts in the current-voltage $(I-V)$ curves of $\mathrm{GFP}^{+}$neurons, increased following S1 (Group $\times$ Cell type $\times$ Current, $F_{(25,1200)}=3.81, p<$ 0.001; Paired: Cell type $\times$ Current, $\left.F_{(25,700)}=6.85, p<0.001\right)$. Similarly, we observed a decrease in the rheobase or current necessary to elicit an action potential (Group $\times$ Cell Type, $F_{(1,49)}=$ $6.64, p<0.05$ ). We observed no other interaction effects for the action potential peak, half-width, threshold, or afterhyperpolarization (both fast and medium). Together, S1 activated a pool of $\mathrm{GFP}^{+}$neurons that were hyperexcitable compared with GFP neurons. This hyperexcitability is associated with conditioning, as it was not observed in $\mathrm{GFP}^{+}$neurons of control mice that received unpaired presentation of sucrose and the cue.

Next, we determined whether the hyperexcitability of neurons activated on $\mathrm{S} 1$ persisted across days following acquisition (Fig. $5 C$ ). To address this question, we tagged neurons activated following S1 in Paired and Unpaired TetTag H2BGFP mice (Tayler et al., 2013) and measured their intrinsic excitability 3-7 d following training under baseline conditions.

We observed no selective alterations in firing capacity $\left(\right.$ Group $\times$ Cell type $\times$ Current, $\left.F_{(12,588)}=1.77, p=0.97\right)$ nor any significant interactions of Group $\times$ Cell Type for all other intrinsic properties (Table 2). We did observe a main effect of Cell Type in the firing capacity $\left(F_{(12,588)}=3.62, p<0.001\right)$ associated with an increase in the $I-V$ curves of $\mathrm{H} 2 \mathrm{~B}-\mathrm{GFP}^{+}$neurons $\left(F_{(25,1225)}=\right.$ $5.01, p<0.001)$, indicating that behaviorally activated dmPFC neurons generally exhibit a mild increased baseline excitability (Fig. 5C; Table 2). Thus, although we did not examine excitability properties related to acute behavioral arousal immediately following $\mathrm{S} 1$ in TetTag H2B-GFP mice, together with the Fos-GFP mice, findings from S1 suggests that the hyperexcitability of the S1-activated neuronal pool is not persistently maintained.

We next determined the excitability properties of neurons activated in late conditioning following S11. We analyzed the excitability of $\mathrm{GFP}^{+}$and $\mathrm{GFP}^{-}$pyramidal cells following S11. We observed no alterations in firing capacity across groups (Fig. $5 B$; Group $\times$ Cell type $\times$ Current, $\left.F_{(12,744)}=1.21, p=0.27\right)$. We did observe a significant interaction effect in the $I-V$ curves (Group $\times$ Cell type $\times$ Current, $F_{(25,1550)}=2.16, p<0.001$ ), underpinned by a GFP ${ }^{-}$increase in Unpaired mice (Cell type $X$ Current, $\left.F_{(25,700)}=2.93, p<0.001\right)$ and a significant fast afterhyperpolarization interaction (Group $\times$ Cell Type, $F_{(1,61)}=4.73$, $p<0.05)$ driven by a GFP ${ }^{-}$decrease in Paired $(p<0.05)$ but not Unpaired $(p=0.50)$ mice, suggesting that some modulation of underlying parameters did occur (Table 1). We detected no other interaction effects in any other measured electrophysiological properties.

To confirm that the hyperexcitability of activated neurons we had observed in S1 was transient, we directly compared the firing capacity of $\mathrm{GFP}^{+}$and $\mathrm{GFP}^{-}$neurons across $\mathrm{S} 1$ and $\mathrm{S} 11$ in Paired mice. As expected, we observed a significant change in firing capacity between S1 and S11 (Session $\times$ Cell type $\times$ Current, $\left.F_{(12,756)}=4.38, p<0.001\right)$. This was driven by an increase in the excitability of $\mathrm{GFP}^{+}$neurons in S1 compared with S11 $\left(F_{(12,384)}\right.$ $=2.70, p<0.01)$ concurrent with a decrease in the excitability of $\mathrm{GFP}^{-}$neurons $\left(F_{(12,372)}=1.81, p<0.05\right)$. Underpinning this alteration was a shift in the $I-V$ curves of Paired mice (Fig. $5 A, B$, inset; Session $\times$ Cell type $\times$ Current, $\left.F_{(25,1550)}=5.02, p<0.001\right)$, due to an increase in $\mathrm{GFP}^{+}$neurons $\left(F_{(25,800)}=3.34, p<0.001\right)$ 


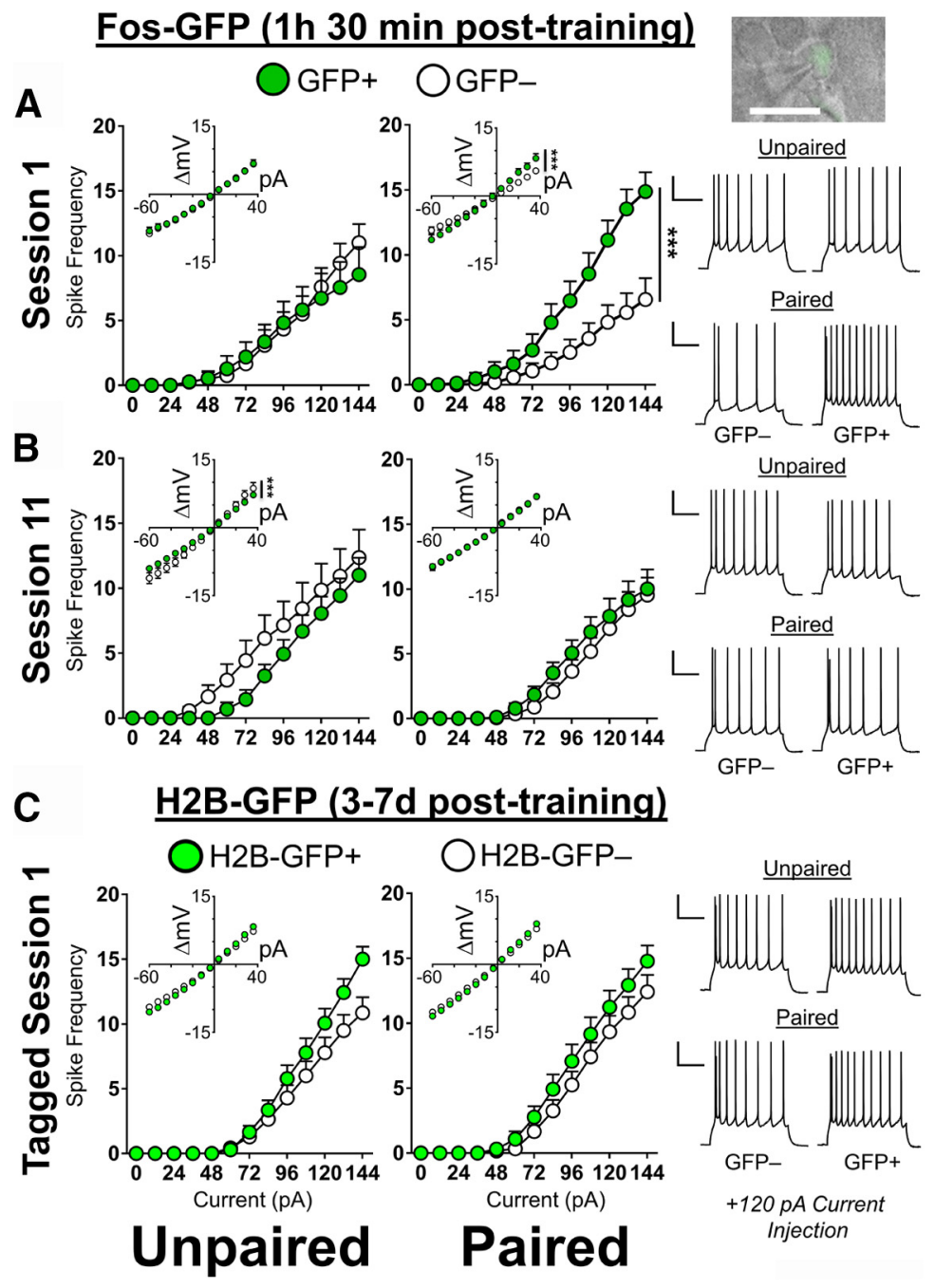

Figure 5. The firing capacity of S1-activated pyramidal cells is enhanced but is not observed several days following S1 or at S11. $A$, Following $\mathrm{S1}_{1, \mathrm{GFP}^{+}}$spike frequency is significantly higher than GFP ${ }^{-}$neurons in Paired, but not Unpaired mice (Paired: GFP ${ }^{+}$ $n=5 / 15, \mathrm{GFP}^{-} n=5 / 16$; Unpaired: GFP $\left.{ }^{+} n=6 / 11, \mathrm{GFP}^{-} n=6 / 12\right)$. B, Following $\mathrm{S}^{-} 1, \mathrm{GFP}^{+}$and GFP ${ }^{-}$spike frequency is similar in both Paired and Unpaired mice (Paired: GFP ${ }^{+} n=6 / 19, \mathrm{GFP}^{-} n=6 / 17$; Unpaired: GFP ${ }^{+} n=6 / 16, \mathrm{GFP}^{-} n=6 / 14$ ). Right top, Representative image of a patched GFP ${ }^{+}$pyramidal cell in the dmPFC of a Fos-GFP mouse. Scale bar, $20 \mu \mathrm{m}$. Right, Representative traces from GFP ${ }^{+}$and GFP ${ }^{-}$pyramidal cells of Paired and Unpaired mice at $120 \mathrm{pA}$ stimulation. C, The spike frequency of neurons activated at $S 1$ of Acquisition returns to baseline 3-7 d following training in TetTag H2B-GFP mice (Paired: ${\mathrm{H} 2 \mathrm{~B}-\mathrm{GFP}^{+}}^{+}=6 / 13,{\mathrm{H} 2 \mathrm{~B}-\mathrm{GFP}^{-}}^{-} n=6 / 12$; Unpaired: ${\mathrm{H} 2 \mathrm{~B}-\mathrm{GFP}^{+}}^{+} n=6 / 14,{\mathrm{H} 2 \mathrm{~B}-\mathrm{GFP}^{-}}^{-} n=6 / 14)$. Right, Representative traces from $\mathrm{H}_{2} \mathrm{~B}-\mathrm{GFP}^{+}$and $\mathrm{H} 2 \mathrm{~B}-\mathrm{GFP}^{-}$pyramidal cells of Paired and Unpaired mice at $120 \mathrm{pA}$ stimulation. Calibration: $25 \mathrm{mV}, 250 \mathrm{~ms}$. Inset, $I-V$ curves. Data are mean \pm SEM. $n=$ number of animals/number of cells total. ${ }^{* *} p<0.001$ (two-way mixed ANOVA Cell type $\times$ (urrent).

and a decrease in $\mathrm{GFP}^{-}$neurons $\left(F_{(25,750)}=1.89, p<0.01\right)$. We also observed a significant change in the medium afterhyperpolarization (Session $\times$ Cell Type, $\left.F_{(1,62)}=10.50, p<0.01\right)$ determined by an increase in $\mathrm{GFP}^{-}$neurons $(p<0.05)$ but not $\mathrm{GFP}^{+}$ neurons at $\mathrm{S} 1$.

In the Unpaired group, we observed no significant changes in firing capacity of $\mathrm{GFP}^{+}$and $\mathrm{GFP}^{-}$neurons between $\mathrm{S} 1$ and $\mathrm{S} 11$ $\left(\right.$ Group $\times$ Cell type $\times$ Current, $\left.F_{(12,588)}=0.88, p=0.57\right)$. We did observe an interaction effect on $\mathrm{S} 1$ and $\mathrm{S} 11 \mathrm{I}-V$ curves (Fig. $5 A, B$, inset; Session $\times$ Cell type $\times$ Current, $\left.F_{(25,1200)}=1.54, p<0.05\right)$, underpinned by an increase in $\mathrm{GFP}^{-}\left(F_{(25,575)}=3.13, p<0.001\right)$ but not $\mathrm{GFP}^{+}\left(F_{(25,625)}=0.45, p=0.99\right)$ neurons and in the rheobase $\left(F_{(1,62)}=4.79, p<0.05\right)$. Together, our findings reveal how hyperexcitability in behaviorally activated neurons occurs via bidirectional modulation of excitability in activated and nonactivated neurons.
Conditioning-selective synaptic alterations are not observed in neurons activated in $\mathrm{S1}$ and $\mathrm{S} 11$

Alterations in synaptic strength are thought to encode associative memories (Takeuchi et al., 2014). We therefore examined glutamatergic presynaptic and postsynaptic function in $\mathrm{GFP}^{+}$and $\mathrm{GFP}^{-}$neurons following S1 and S11. We assessed synaptic strength using the AMPAR/NMDAR ratio, SEPSC, and presynaptic release properties using PPRs. AMPAR/NMDAR ratios (Fig. $6 A$; Group $\times$ Cell Type, $F_{(1,19)}=$ $0.39, p=0.54$ ), sEPSC frequency (Fig. $6 B$; Group $\times$ Cell Type, $F_{(1,73)}=1.75, p=$ 0.19 ), and amplitude (Fig. 6C; Group $\times$ Cell Type, $\left.F_{(1,73)}=0.74, p=0.39\right)$, and PPRs (Fig. $6 D$; Stimulus Interval $\times$ Group $\times$ Cell Type, $F_{(6,156)}=0.38, p=$ $0.89)$ were not modulated in S1.

Equally, following S11, we measured no significant interaction for AMPAR/ NMDAR ratios (Fig. $6 A$; Group $\times$ Cell Type, $\left.F_{(1,19)}=0.01, p=0.92\right)$, although there was a main effect of Cell Type $\left(F_{(1,19)}\right.$ $=5.66, p<0.05)$. Furthermore, we found no interaction effects for the sEPSC frequency (Fig. 6B; Group $\times$ Cell Type, $F_{(1,76)}=0.20, p=0.66$ ) or amplitude (Fig. $6 C$; Group $\times$ Cell Type $F_{(1,76)}=0.05, p=$ $0.83)$. However, we detected a main effect of Cell Type on the sEPSC frequency (Cell Type, $\left.F_{(1,76)}=12.41, p<0.001\right)$. This frequency alteration was not due to changes in presynaptic function (Fig. $6 D$; Stimulus Interval $\times$ Group $\times$ Cell Type, $F_{(6,150)}=$ $1.01, p=0.42)$.

\section{Connectivity changes are not observed in neurons activated in $\mathrm{S} 1$ and $\mathrm{S} 11$} Increased connectivity between neurons is thought to facilitate the establishment of CS-US representations (Ryan et al., 2015; Choi et al., 2018). We thus targeted $\mathrm{GFP}^{+}$and $\mathrm{GFP}^{-}$neurons with paired electrophysiological recordings to determine whether appetitive conditioning increased ensemble connectivity. We analyzed the probability of a connection between $\mathrm{GFP}^{+}$to $\mathrm{GFP}^{+}(+/+), \mathrm{GFP}^{+}$to $\mathrm{GFP}^{-}$ $(+/-)$ and $\mathrm{GFP}^{-}$to $\mathrm{GFP}^{+}(-/+)$neurons across groups on $\mathrm{S} 1$ and S11 (Fig. 7A). Average connectivity probability was $9.88 \%$ between pyramidal pairs, in line with previous reports (Markram et al., 1997). We observed no change in connection probability between any neuron type in S1 and S11 (Fisher's exact test; Group $\times$ Connection, S1: $+/+, p=0.61 ;+/-, p=0.23 ;-1+$, $p=0.34$; S11: $+/+, p=1.00 ;+/-, p=1.00 ;-/+, p=1.00$; Fig. $7 B)$.

\section{Persistent excitability enhancement of S1-activated neurons impairs learning}

Neurons activated during S1 were hyperexcitable when mice did not exhibit cue-selective food seeking. To examine their behavioral role, we tagged neurons activated during S1 with the excit- 
atory DREADD hM3Dq in Fos-tTA mice using the TetTag DREADD approach (Fig. $8 A, B$ ) (Zhang et al., 2015). We repeatedly activated these tagged neurons using systemic injections of the hM3Dq agonist clozapine $(0.1 \mathrm{mg} / \mathrm{kg})$ (Gomez et al., 2017) to artificially enhance excitability throughout conditioning. This compound is a metabolite of the widely used hM3Dq agonist clozapine- $N$-oxide, and has recently been shown to serve as the agonist at hM3Dq in vivo (Gomez et al., 2017). Fos- $t$ TA mice and control WT mice not tagged with hM3Dq underwent acquisition and recall test sessions as before.

During acquisition (Fig. 8D), there was a significant interaction effect of Cue $\times$ Session $\left(F_{(11,176)}=6.94, p<0.001\right)$ and a significant effect of Cue during Recall (Fig. $8 E ; F_{(1,16)}=9.03, p<0.01$ ) on discriminated approach performance. Moreover, we observed a significant interaction effect of Cue $\times$ Session $\times$ hM3Dq $\left(F_{(11,176)}=2.00, p<0.05\right)$ on the number of responses (Fig. 8D). As before, we calculated the Selectivity Index (Fig. 8C) and found a significant interaction of hM3Dq $\times$ Session $\left(F_{(11,176)}=3.81, p<\right.$ $0.001)$, and post hoc testing revealed significantly decrease cue-selective responding in Fos-tTA mice on a number of sessions $(p<0.05)$. Thus, persistently enhancing the excitability of S1-activated neurons interfered with conditioning. During the test for recall, we observed a near significant interaction of hM3Dq $\times$ Cue (Fig. $\left.8 E ; F_{(1,16)}=3.82, p=0.068\right)$ on the number of approach responses.

To confirm that these effects were relevant to S1-activated neurons, we repeatedly enhanced the excitability of neurons tagged following exposure to a neutral, NC exposure (Fig. $8 F$ ). The exposure procedure activates neurons that are distinct from those activated by discrete (wouldbe) appetitive cues (Fanous et al., 2012; Cruz et al., 2013). We observed a significant interaction effect of Cue $\times$ Session on approach responses during acquisition $\left(F_{(11,176)}=5.19, p<0.001\right)$ and a significant effect of Cue during recall $\left(F_{(1,16)}=45.53, p<0.001\right.$; Fig. $8 H)$, again indicating robust conditioning in our procedure. However, we observed no significant effect of hM3Dq in acquisition (Fig. 8G) on the number of approach responses, and analysis of the Selectivity Index also revealed no significant interaction effect of hM3Dq $\times \operatorname{Session}\left(F_{(11,176)}=0.32, p=0.97\right.$; Fig. $8 F$ ). Furthermore, we did not observe a significant interaction effect of hM3Dq $\times$ Cue on the number of responses during recall (Fig. $8 H ; F_{(1,16)}=0.32, p=0.88$ ). Thus, in contrast to S1-tagged neurons, persistently enhancing the excitability of NCtagged neurons did not affect conditioning.

Of note, all sessions in which clozapine was delivered were performed in the afternoon, closer to feeding time. We have pre-
Session 1 Session 11

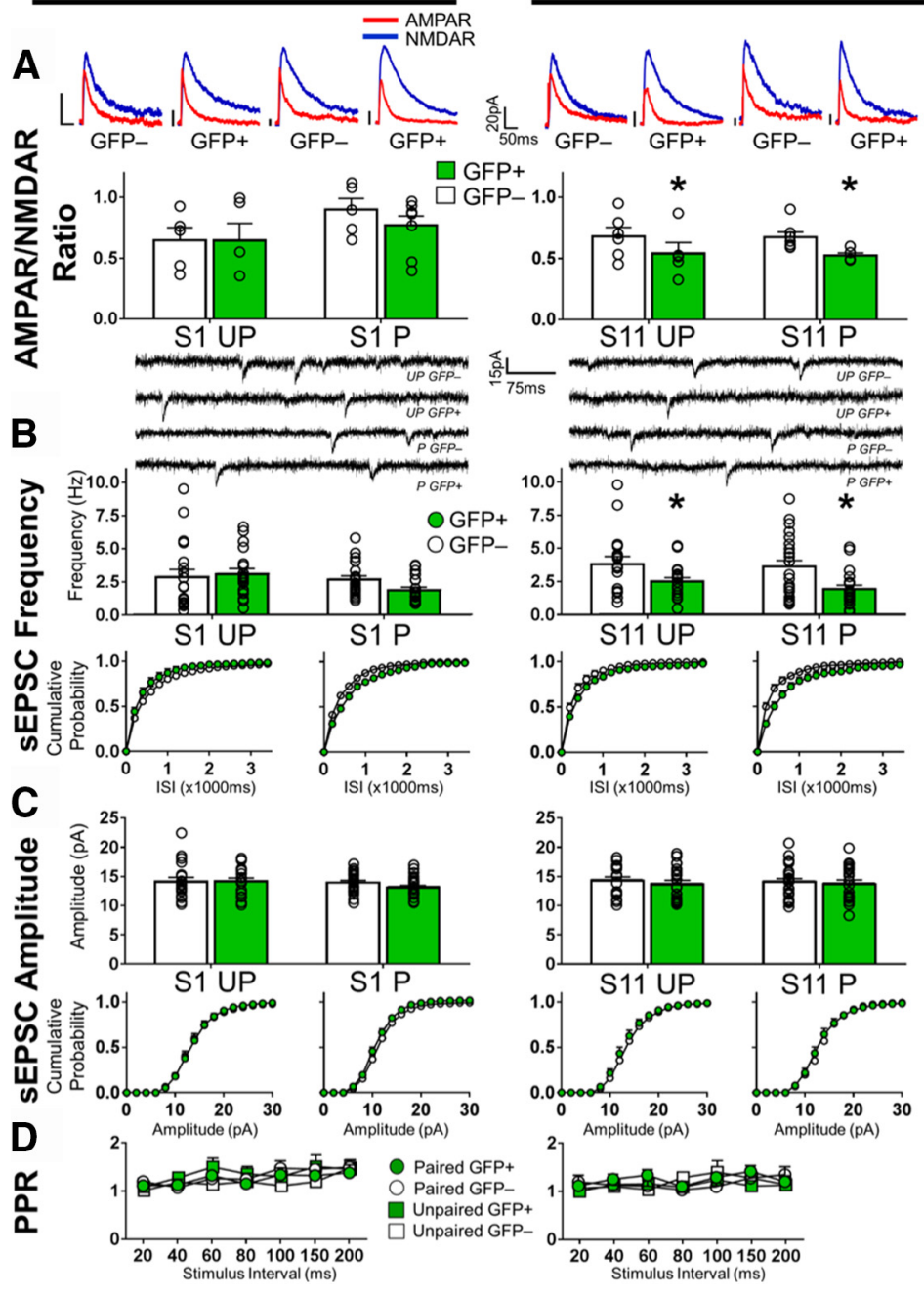

Figure 6. Conditioning-selective synaptic alterations are not observed in neurons activated on $S 1$ and $S 11$. $A$, No differences in AMPAR/NMDAR ratios between GFP ${ }^{+}$and GFP ${ }^{-}$neurons in $\mathrm{S} 1$ in Paired and Unpaired mice (Paired: $\mathrm{GFP}^{+} n=6 / 8, \mathrm{GFP}^{-} n=$ 4/5 Unpaired: GFP $\left.{ }^{+} n=4 / 5, \mathrm{GFP}^{-} n=5 / 5\right)$. Decreased AMPAR/NMDAR ratios in GFP ${ }^{+}$neurons in $\mathrm{S} 11$ in Paired and Unpaired AMPA/NMDAR recordings from layers II/III dmPFC pyramidal cells. Calibration: $20 \mathrm{pA}, 50 \mathrm{~ms}$. $\boldsymbol{B}$, No differences in the frequency of SEPSCs between GFP ${ }^{+}$and GFP ${ }^{-}$neurons in S1 in Paired and Unpaired mice. Decreased sEPSC frequency in GFP ${ }^{+}$neurons in S11 Cumulative probability plots of sEPSC frequency. $\boldsymbol{C}$, No differences in SEPSC amplitudes between GFP ${ }^{+}$and GFP ${ }^{-}$neurons in S1 and S11. Bottom, Cumulative probability plots of SEPSC amplitudes (S1:Paired:GFP ${ }^{+} n=8 / 19, \mathrm{GFP}^{-} n=8 / 21$; Unpaired: GFP ${ }^{+}$ D, No differences in PPRs of GFP ${ }^{+}$and GFP ${ }^{-}$neurons in S1 and S11 (Paired: GFP ${ }^{+} n=7 / 8, \mathrm{GFP}^{-} n=7 / 9$; Unpaired: GFP ${ }^{+} n=$ 4/6, GFP ${ }^{-} n=5 / 7, \mathrm{~S} 11:$ Paired: GFP ${ }^{+} n=8 / 9, \mathrm{GFP}^{-} n=7 / 7$; Unpaired: GFP $\left.{ }^{+} n=7 / 7, \mathrm{GFP}^{-} n=6 / 6\right)$. Data are mean \pm SEM. $n=$ number of animals/number of cells total. *Main effect of Cell Type in a two-way ANOVA $p<0.05$.

viously observed in our that PM sessions often show poorer response selectivity than AM session in our task (Fig. 1C). Thus, while we did observe decreased performances at sessions 2, 4, 6, 8, 10 , and 12 , this is not likely due to clozapine delivery.

\section{Discussion}

We show that the establishment of a CS-US association and cueselective food-seeking is associated with the recruitment of a stable, repeatedly activated subset of pyramidal cells in the dmPFC from a wider pool of neurons activated in the initial conditioning session (S1), when mice did not exhibit cue-selective foodseeking. A minority (29\%) of pyramidal cells from this wider pool of candidate neurons were recruited into this ensemble. This 
A

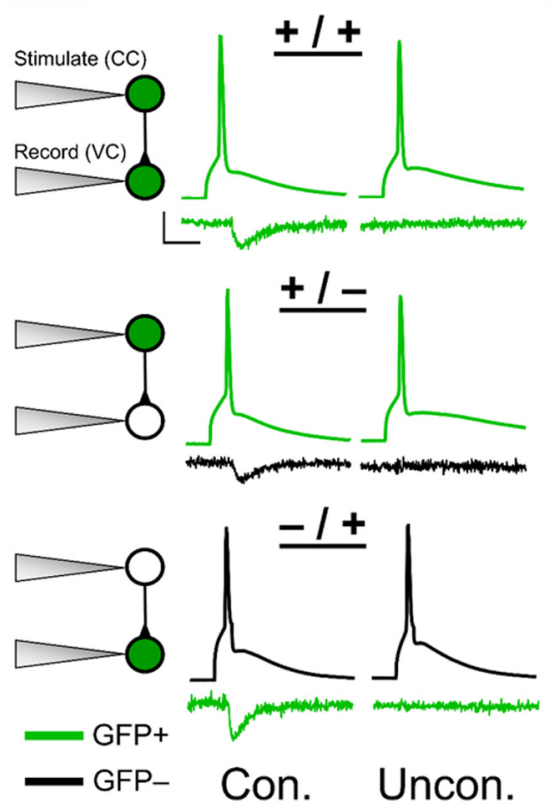

B

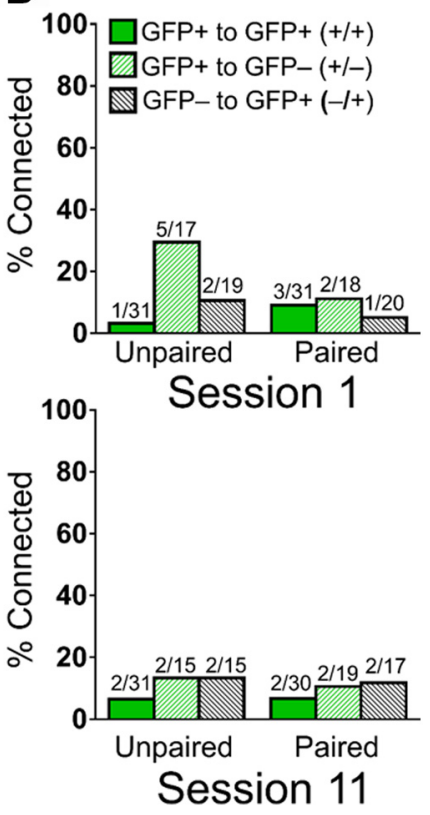

Figure 7. No connectivity differences between GFP ${ }^{+}$neurons and between GFP ${ }^{+}$and GFP ${ }^{-}$neurons across Paired and Unpaired groups in S1 and S11. A, Representative traces of connected (Con.) and unconnected (Uncon.) pairs recorded from a $\mathrm{GFP}^{+}$to $\mathrm{GFP}^{+}$neuron $(+/+), \mathrm{GFP}^{+}$to $\mathrm{GFP}^{-}$neuron $(+/-)$, and $\mathrm{GFP}^{-}$to $\mathrm{GFP}^{+}$neuron $(-/+)$. Neurons were stimulated in current clamp (CC) and postsynaptic excitatory currents recorded in voltage clamp (VC). Calibration: $25 \mathrm{mV}$ (CC)/25 pA (VC), 10 ms. $\boldsymbol{B}$, Percentage of $+/+,+/-$, and $-/+$ connections in Paired and Unpaired mice from S1 and S11. There were no significant alterations in connectivity between groups.

recruitment was indicated by consistent reactivation across conditioning and in memory recall. S1-activated neurons exhibited hyperexcitability, which was not observed at later stages of conditioning when mice acquired cue-selective food seeking. Repeatedly enhancing the excitability of S1-tagged neurons during conditioning disrupted acquisition of a cuediscriminated appetitive performance. We provide novel insights into neuronal ensemble formation and how they may encode cue-evoked appetitive memories that control food seeking. Moreover, we identify a potential mechanism that determines which neurons become incorporated to form these ensembles.

\section{Appetitive memory formation recruits a stable group of pyramidal cells from the initial conditioning session}

CS-activated neurons are a small subset ( $\sim 6 \%-12 \%)$ of the total neuronal population (Bossert et al., 2011; Fanous et al., 2012), and their selective silencing in the $\mathrm{mPFC}$ disrupts reward seeking, indicating their role in CS-US memory encoding (Bossert et al., 2011; Suto et al., 2016). However, these studies did not examine whether a subgroup of these neurons were repeatedly activated during learning. During CS-evoked memory recall, we revealed increased recruitment of a pyramidal cell ensemble that exhibited a stable activation history during conditioning, suggesting its role in cue-selective food seeking. These stably activated neurons were originally recruited in the initial conditioning session, and that activation history may influence their inclusion into a conditioning ensemble. Moreover, only 23\% of neurons activated during memory recall exhibited persistent activation throughout acquisition. Our findings illuminate how a subgroup of neurons within a population of CS-activated neurons may encode a CS-US memory. They raise the intriguing possibility that methods which manipulate appetitive behaviors by silencing CS-activated neurons
(Suto et al., 2016) may exert their effects through such a neuronal subgroup with a repeated learning activation history. However, the tools to selectively manipulate this subgroup to confirm this idea are currently unavailable. Finally, in general, more neurons were persistently activated in all sessions compared with neurons activated in mid and late, but not early conditioning, a similar pattern also observed in Recall-activated neurons. Since mPFC neurons participate in contextual encoding during exploration (Hyman et al., 2012), such persistently activated neurons may encode environmental features of the training context following its repeated exposure.

We did not observe the enhanced recruitment of a repeatedly activated subset of interneurons during conditioning and memory recall (Fig. 4C,F). However, we did observe an increased reactivation likelihood following $\mathrm{S} 1$ at an overall population level (Fig. 4D,G). These seemingly discrepant findings may arise from individual variability across mice, which the population analysis does not consider. Also, we did not account for the various interneuron subclasses with different functional characteristics, which exhibit differential activity during foodseeking (Gaykema et al., 2014). Moreover, in the hippocampus certain interneuron subclasses are recruited during learning and regulate excitatory ensemble recruitment (Stefanelli et al., 2016), and hippocampal interneurons exhibit excitability alterations following conditioning (McKay et al., 2013). Additional work is necessary to elucidate the role of specific dmPFC interneuron subtypes and their excitability alterations during appetitive conditioning.

\section{Conditioning-related parameters modulate the excitability of} behaviorally activated neurons

We identified a hyperexcitable pool of pyramidal cells activated on the initial, but not late conditioning session in Paired mice. These excitability alterations might be related to temporally contiguous CS and US presentations, as they were not observed in $\mathrm{GFP}^{+}$neurons of Unpaired mice that received CS and US presentations at disparate times. Currently, we cannot rule out whether this hyperexcitability was present before S1. Therefore, in Paired mice, a preexisting elevated baseline excitability may have rendered certain neurons to become activated in S1 and thus express GFP (Yiu et al., 2014; Gouty-Colomer et al., 2016).

The hyperexcitability in Fos-GFP mice following conditioning was observed several hours after behavioral testing. This prolonged excitability increase may induce long-term plasticity, which functions to promote memory consolidation following the conditioning session, by facilitating ensemble reactivation that occurs many hours following training (de Sousa et al., 2019). An interesting future investigation is to determine how a baseline or training-induced hyperexcitability of dmPFC S1-activated neurons influences ensemble recruitment. However, a direct link between such hyperexcitability and ensemble recruitment is dif- 
A
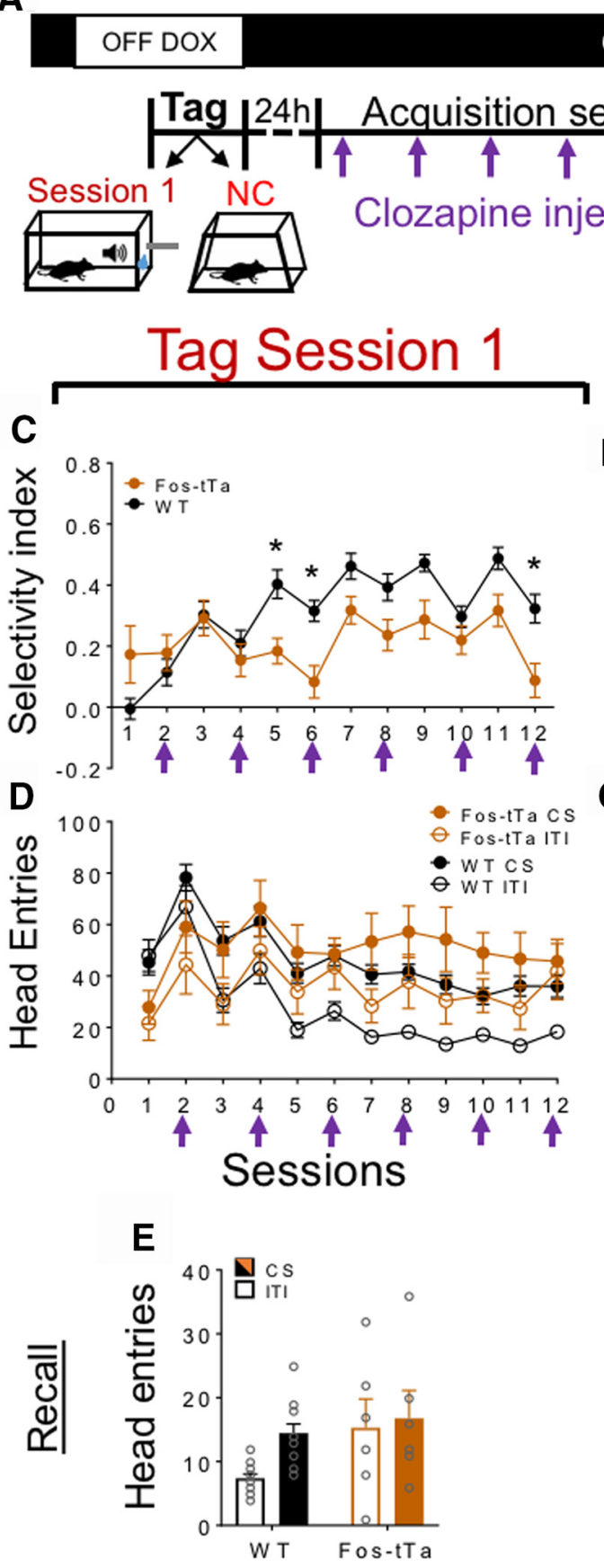

ON DOX

B
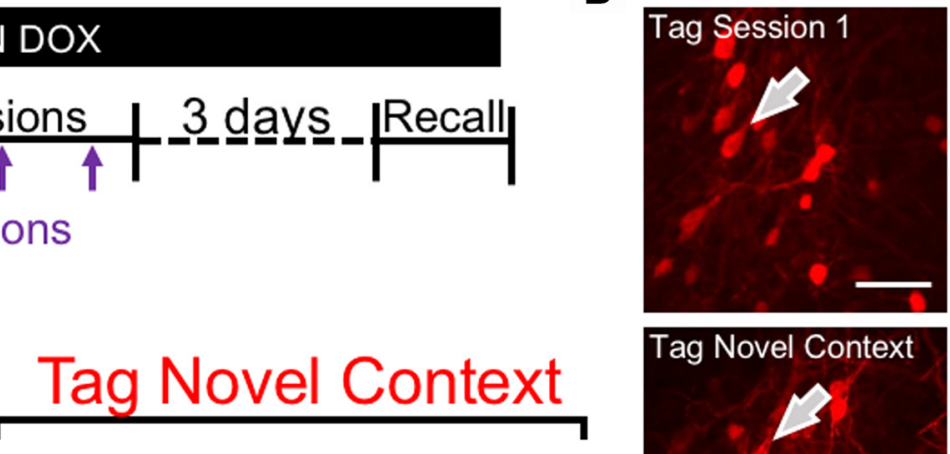

$\mathbf{F}$

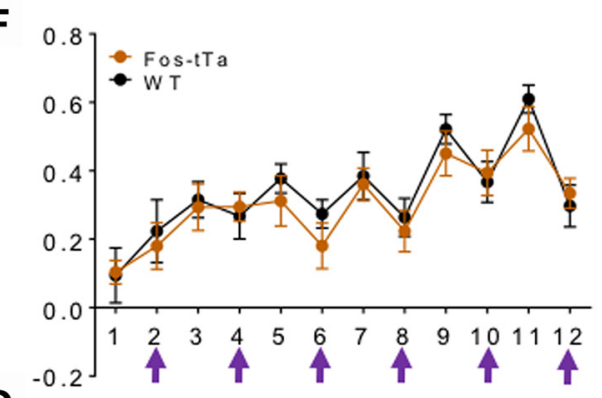

G

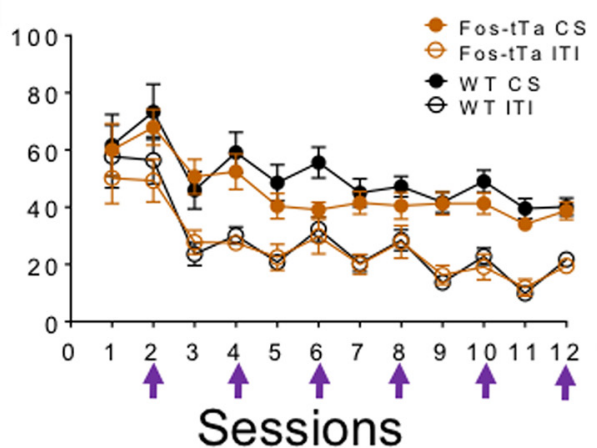

Tag Novel Context

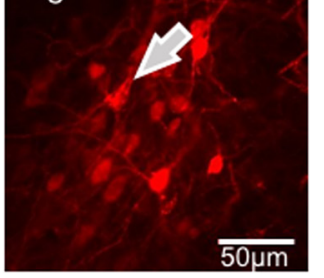

1

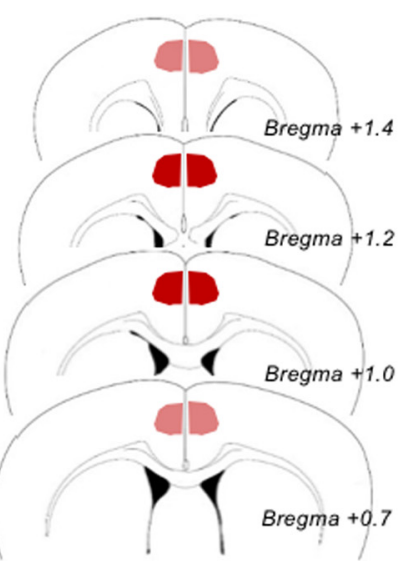

H

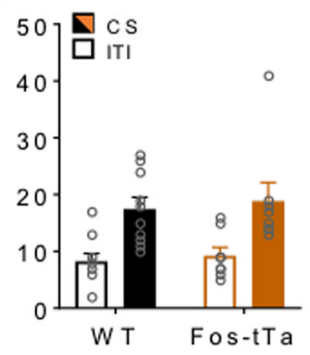

Figure 8. Persistently enhancing the excitability of $\mathrm{S1}$-activated neurons impairs conditioning. $\boldsymbol{A}$, Timeline of tagging and conditioning. All mice received clozapine injections on Sessions 2, 4, 6, 8, 10, and 12 (purple arrows). Doxycycline was presented in the drinking water of all mice at all times, with the exception of its removal $48 \mathrm{~h}$ before the tagging session, which lasted until $1 \mathrm{~h}$ following the tagging session. $\boldsymbol{B}$, Representative image of mCherry staining in dmPFC of Fos-tTa mice tagged during $\mathrm{S} 1$ or by exposure to a NC. Arrows indicate $\mathrm{hM} 3 \mathrm{Dq}^{+}$neurons. C, $\boldsymbol{F}$, Selectivity Index of responses (CS-ITI/total number head entries) during acquisition in Fos-tTA (hM3Dq ${ }^{+}$; orange) and WT (hM3Dq ${ }^{-}$; black) mice following S1 or NC tagging. $\boldsymbol{D}, \mathbf{G}, \mathrm{CS}$ and ITI responses during Acquisition in Fos-tTA (hM3Dq ${ }^{+}$; orange) and WT (hM3Dq ${ }^{-}$; black) mice following $\mathrm{S1}$ or NC tagging. $\boldsymbol{E}, \boldsymbol{H}, \mathrm{CS}$ and ITI responses during recall in Fos-tTA (hM3Dq ${ }^{+}$; orange) and $\mathrm{WT}\left(\mathrm{hM} \mathrm{Dqq}^{-}\right.$; black) mice following S1 or NC tagging. I, Schematic representation of injection sites. Data are mean \pm SEM. ${ }^{*} p<0.05 . S 1$ tag $=$ 6,$12 ; N C \operatorname{tag}: n=8,10$.

ficult to establish. Currently, we cannot identify and measure the excitability in vivo from those S1-activated neurons that will become recruited to the ensemble throughout conditioning. Nevertheless, the proposed roles of hyperexcitability in memory and our imaging findings raise the possibility that the stable conditioning-related ensemble emerges from a hyperexcitable neuronal pool activated in the initial conditioning session.
Implications of excitability alterations on behaviorally activated neurons

Chemogenetically enhancing the excitability of the neuronal pool activated in S1 throughout conditioning interfered with mice acquiring a reliable cue-evoked food-seeking response. Thus, the dissipation of neuronal hyperexcitability may be necessary to acquire robust cue-evoked food seeking. However, in a study by 
Volle et al. (2016), increasing mPFC hyperexcitability using widespread hM3Dq expression resulted in potentiated trace conditioning. They proposed that this manipulation facilitated animals to acquire low-grade associations (e.g., under conditions of low temporal contiguity or poor contingency) that would otherwise fail to support robust learning. Therefore, our mice with enhanced excitability may have learned relevant, but also irrelevant or spurious associations between the US and other stimuli (or interoceptive events), leading to disrupted discriminative performance. In support, lesion studies suggest that the dmPFC promotes the formation of relevant and precise associations that enable proper cue discrimination (Bussey et al., 1997; Parkinson et al., 2000; Cardinal et al., 2002). Although we used activitybased tagging, our DREADD manipulation was not cell-type specific. However, we observed that the vast majority of $\mathrm{GFP}^{+}$ neurons were pyramidal cells (Fig. 3D), consistent with our recent study (Ziminski et al., 2017).

From a behavior ecology perspective, MacArthur and Pianka (1966) theorized that animals would tend toward optimal foraging behaviors in which they minimize time and energy spent food seeking. In our learning task, this is related to reduced nonspecific responses (i.e., high Selectivity Index). We observed attenuated selectivity and high nonselective responses following repeated chemogenetic excitability enhancements of S1-activated neurons. Collectively, we theorize that early conditioning activates a hyperexcitable neuronal pool in the dmPFC to facilitate the selection of neurons into a stable ensemble that eventually supports a robust CS-US association. Given the role of the dmPFC in attention and motivation (Parkinson et al., 2000; Cardinal et al., 2002; Totah et al., 2009; Bryden et al., 2011), neuronal hyperexcitability helps engage these processes during initial CS-US formation. However, this hyperexcitability nonselectively amplifies environmental stimuli and decreases the signal-to-noise ratio of extracted information. Therefore, this excitability needs to renormalize during the transition from nonselective to selective responding to food cues, to promote to optimal food-seeking.

\section{No observed learning-relevant changes in synaptic properties and connectivity}

We observed no selective learning-induced changes in the synaptic strength nor connectivity of activated neurons, in contrast to other observations following establishment of aversive associations (Ryan et al., 2015; Gouty-Colomer et al., 2016; Choi et al., 2018). Several factors may have contributed to this difference. First, mice received sucrose under food restriction, which can induce synaptic strength alterations (Peng et al., 2015). We observed decreases in AMPAR/NMDAR ratios and sEPSC frequency in $\mathrm{GFP}^{+}$neurons in Paired and Unpaired mice at S11. Thus, synaptic alterations in neurons repeatedly activated by sucrose may have masked learning-related synaptic adaptations that contribute to stable ensemble formation. Also, mPFC synaptic changes may not occur immediately following learning but develop later in a hippocampal-dependent process (Restivo et al., 2009). Thus, a prolonged delay following appetitive learning (e.g., weeks) that is associated with memory engram maturation (Kitamura et al., 2017) may better reveal learning-selective synaptic changes. Finally, recent studies have demonstrated learning-induced increases in ensemble intraconnectivity by using optogenetic ensemble stimulation in one brain area while recording from a target ensemble neurons in another (Ryan et al., 2015; Choi et al., 2018). Our lack of observed connectivity changes may be due to utilization of paired recordings, in which connections between individual activated neurons were locally assessed rather than across two different brain areas.

\section{Conclusions and future directions}

In conclusion, despite appetitive conditioning's importance in survival, few studies have established its precise mechanisms at the neuronal ensemble level in the mPFC. We provide the initial key evidence regarding dmPFC ensemble recruitment and corresponding excitability alterations that reflect different stages of optimal food-seeking. Further investigations are necessary to determine which hyperexcitable neurons activated early in our conditioning procedure will become allocated to the CS-US ensemble. Hence, tools to measure neuronal excitability and recruitment in vivo need to be developed to identify the properties that determine this recruitment process. This will allow us to better grasp the principles that govern neuronal ensemble recruitment and its alterations for establishing associative memories.

\section{References}

Barth AL, Gerkin RC, Dean KL (2004) Alteration of neuronal firing properties after in vivo experience in a FosGFP transgenic mouse. J Neurosci 24:6466-6475.

Beasley TM, Schumacker RE (1995) Multiple regression approach to analyzing contingency tables: post hoc and planned comparison procedures. J Exp Educ 64:79-93.

Besser S, Sicker M, Marx G, Winkler U, Eulenburg V, Hülsmann S, Hirrlinger J (2015) A transgenic mouse line expressing the red fluorescent protein tdTomato in GABAergic neurons. PLoS One 10:e0129934.

Bolte S, Cordelières FP (2006) A guided tour into subcellular colocalization analysis in light microscopy. J Microsc 224:213-232.

Bossert JM, Stern AL, Theberge FR, Cifani C, Koya E, Hope BT, Shaham Y (2011) Ventral medial prefrontal cortex neuronal ensembles mediate context-induced relapse to heroin. Nat Neurosci 14:420-422.

Bryden DW, Johnson EE, Tobia SC, Kashtelyan V, Roesch MR (2011) Attention for learning signals in anterior cingulate cortex. J Neurosci 31: 18266-18274.

Bussey TJ, Everitt BJ, Robbins TW (1997) Dissociable effects of cingulate and medial frontal cortex lesions on stimulus-reward learning using a novel Pavlovian autoshaping procedure for the rat: implications for the neurobiology of emotion. Behav Neurosci 111:908-919.

Cao VY, Ye Y, Mastwal S, Ren M, Coon M, Liu Q, Costa RM, Wang KH (2015) Motor learning consolidates arc-expressing neuronal ensembles in secondary motor cortex. Neuron 86:1385-1392.

Cao XY, Xu H, Wu LJ, Li XY, Chen T, Zhuo M (2009) Characterization of intrinsic properties of cingulate pyramidal neurons in adult mice after nerve injury. Mol Pain 5:73.

Cardinal RN, Parkinson JA, Lachenal G, Halkerston KM, Rudarakanchana N, Hall J, Morrison CH, Howes SR, Robbins TW, Everitt BJ (2002) Effects of selective excitotoxic lesions of the nucleus accumbens core, anterior cingulate cortex, and central nucleus of the amygdala on autoshaping performance in rats. Behav Neurosci 116:553-567.

Carthey AJ, Bytheway JP, Banks PB (2011) Negotiating a noisy, informationrich environment in search of cryptic prey: olfactory predators need patchiness in prey cues. J Anim Ecol 80:742-752.

Choi JH, Sim SE, Kim JI, Choi DI, Oh J, Ye S, Lee J, Kim T, Ko HG, Lim CS, Kaang BK (2018) Interregional synaptic maps among engram cells underlie memory formation. Science 360:430-435.

Cifani C, Koya E, Navarre BM, Calu DJ, Baumann MH, Marchant NJ, Liu QR, Khuc T, Pickel J, Lupica CR, Shaham Y, Hope BT (2012) Medial prefrontal cortex neuronal activation and synaptic alterations after stressinduced reinstatement of palatable food seeking: a study using c-fos-GFP transgenic female rats. J Neurosci 32:8480-8490.

Cruz FC, Koya E, Guez-Barber DH, Bossert JM, Lupica CR, Shaham Y, Hope BT (2013) New technologies for examining the role of neuronal ensembles in drug addiction and fear. Nat Rev Neurosci 14:743-754.

Cruz FC, Babin KR, Leao RM, Goldart EM, Bossert JM, Shaham Y, Hope BT (2014) Role of nucleus accumbens shell neuronal ensembles in contextinduced reinstatement of cocaine-seeking. J Neurosci 34:7437-7446.

de Sousa AF, Cowansage KK, Zutshi I, Cardozo LM, Yoo EJ, Leutgeb S, Mayford M (2019) Optogenetic reactivation of memory ensembles in 
the retrosplenial cortex induces systems consolidation. Proc Natl Acad Sci U S A 116:8576-8581.

Fanous S, Goldart EM, Theberge FR, Bossert JM, Shaham Y, Hope BT (2012) Role of orbitofrontal cortex neuronal ensembles in the expression of incubation of heroin craving. J Neurosci 32:11600-11609.

Gaykema RP, Nguyen XM, Boehret JM, Lambeth PS, Joy-Gaba J, Warthen DM, Scott MM (2014) Characterization of excitatory and inhibitory neuron activation in the mouse medial prefrontal cortex following palatable food ingestion and food driven exploratory behavior. Front Neuroanat 8:60.

Gomez JL, Bonaventura J, Lesniak W, Mathews WB, Sysa-Shah P, Rodriguez LA, Ellis RJ, Richie CT, Harvey BK, Dannals RF, Pomper MG, Bonci A, Michaelides M (2017) Chemogenetics revealed: DREADD occupancy and activation via converted clozapine. Science 357:503-507.

Gouty-Colomer LA, Hosseini B, Marcelo IM, Schreiber J, Slump DE, Yamaguchi S, Houweling AR, Jaarsma D, Elgersma Y, Kushner SA (2016) Arc expression identifies the lateral amygdala fear memory trace. Mol Psychiatry 21:364-375.

Guzman SJ, Schlögl A, Schmidt-Hieber C (2014) Stimfit: quantifying electrophysiological data with python. Front Neuroinform 8:16.

Hyman JM, Ma L, Balaguer-Ballester E, Durstewitz D, Seamans JK (2012) Contextual encoding by ensembles of medial prefrontal cortex neurons. Proc Natl Acad Sci U S A 109:5086-5091.

Jansen A (1998) A learning model of binge eating: cue reactivity and cue exposure. Behav Res Ther 36:257-272.

Kitamura T, Ogawa SK, Roy DS, Okuyama T, Morrissey MD, Smith LM, Redondo RL, Tonegawa S (2017) Engrams and circuits crucial for systems consolidation of a memory. Science 356:73-78.

Koya E, Uejima JL, Wihbey KA, Bossert JM, Hope BT, Shaham Y (2009) Role of ventral medial prefrontal cortex in incubation of cocaine craving. Neuropharmacology 56 [Suppl 1]:177-185.

Koya E, Cruz FC, Ator R, Golden SA, Hoffman AF, Lupica CR, Hope BT (2012) Silent synapses in selectively activated nucleus accumbens neurons following cocaine sensitization. Nat Neurosci 15:1556-1562.

Low RJ, Gu Y, Tank DW (2014) Cellular resolution optical access to brain regions in fissures: imaging medial prefrontal cortex and grid cells in entorhinal cortex. Proc Natl Acad Sci U S A 111:18739-18744.

MacArthur RH, Pianka ER (1966) On optimal use of a patchy environment. Am Naturalist 100:603-609.

Markram H, Lübke J, Frotscher M, Roth A, Sakmann B (1997) Physiology and anatomy of synaptic connections between thick tufted pyramidal neurones in the developing rat neocortex. J Physiol 500:409-440.

Mattson BJ, Koya E, Simmons DE, Mitchell TB, Berkow A, Crombag HS, Hope BT (2008) Context-specific sensitization of cocaine-induced locomotor activity and associated neuronal ensembles in rat nucleus accumbens. Eur J Neurosci 27:202-212.

McKay BM, Oh MM, Disterhoft JF (2013) Learning increases intrinsic excitability of hippocampal interneurons. J Neurosci 33:5499-5506.

Parkinson JA, Willoughby PJ, Robbins TW, Everitt BJ (2000) Disconnection of the anterior cingulate cortex and nucleus accumbens core impairs Pavlovian approach behavior: further evidence for limbic cortical-ventral striatopallidal systems. Behav Neurosci 114:42-63.

Pavlov IP (1927) Conditioned reflexes. Oxford: Oxford UP.

Paxinos G, Franklin K (2001) The mouse brain atlas in stereotaxic coordinates. San Diego: Academic.

Peng XX, Lister A, Rabinowitsch A, Kolaric R, Cabeza de Vaca S, Ziff EB, Carr $\mathrm{KD}$ (2015) Episodic sucrose intake during food restriction increases synaptic abundance of AMPA receptors in nucleus accumbens and augments intake of sucrose following restoration of ad libitum feeding. Neuroscience 295:58-71.

Pologruto TA, Sabatini BL, Svoboda K (2003) ScanImage: flexible software for operating laser scanning microscopes. Biomed Eng Online 2:13.

Restivo L, Vetere G, Bontempi B, Ammassari-Teule M (2009) The formation of recent and remote memory is associated with time-dependent formation of dendritic spines in the hippocampus and anterior cingulate cortex. J Neurosci 29:8206-8214.

Riebe I, Seth H, Culley G, Dósa Z, Radi S, Strand K, Fröjd V, Hanse E (2016)
Tonically active NMDA receptors: a signalling mechanism critical for interneuronal excitability in the CA1 stratum radiatum. Eur J Neurosci 43:169-178.

Riga D, Matos MR, Glas A, Smit AB, Spijker S, Van den Oever MC (2014) Optogenetic dissection of medial prefrontal cortex circuitry. Front Syst Neurosci 8:230.

Ryan TJ, Roy DS, Pignatelli M, Arons A, Tonegawa S (2015) Engram cells retain memory under retrograde amnesia. Science 348:1007-1013.

Schindelin J, Arganda-Carreras I, Frise E, Kaynig V, Longair M, Pietzsch T, Preibisch S, Rueden C, Saalfeld S, Schmid B, Tinevez JY, White DJ, Hartenstein V, Eliceiri K, Tomancak P, Cardona A (2012) Fiji: an opensource platform for biological-image analysis. Nat Methods 9:676-682.

Stefanelli T, Bertollini C, Lüscher C, Muller D, Mendez P (2016) Hippocampal somatostatin interneurons control the size of neuronal memory ensembles. Neuron 89:1074-1085.

Suto N, Laque A, De Ness GL, Wagner GE, Watry D, Kerr T, Koya E, Mayford MR, Hope BT, Weiss F (2016) Distinct memory engrams in the infralimbic cortex of rats control opposing environmental actions on a learned behavior. Elife 5:e21920.

Takeuchi T, Duszkiewicz AJ, Morris RG (2014) The synaptic plasticity and memory hypothesis: encoding, storage and persistence. Philos Trans R Soc Lond B Biol Sci 369:20130288.

Tayler KK, Tanaka KZ, Reijmers LG, Wiltgen BJ (2013) Reactivation of neural ensembles during the retrieval of recent and remote memory. Curr Biol 23:99-106.

Thévenaz P, Ruttimann UE, Unser M (1998) A pyramid approach to subpixel registration based on intensity. IEEE Trans Image Process 7:27-41.

Ting JT, Daigle TL, Chen Q, Feng G (2014) Acute brain slice methods for adult and aging animals: application of targeted patch clamp analysis and optogenetics. Methods Mol Biol 1183:221-242.

Totah NK, Kim YB, Homayoun H, Moghaddam B (2009) Anterior cingulate neurons represent errors and preparatory attention within the same behavioral sequence. J Neurosci 29:6418-6426.

Tumbar T, Guasch G, Greco V, Blanpain C, Lowry WE, Rendl M, Fuchs E (2004) Defining the epithelial stem cell niche in skin. Science 303: $359-363$.

van den Akker K, Schyns G, Jansen A (2018) Learned overeating: applying principles of Pavlovian conditioning to explain and treat overeating. Curr Addict Rep 5:223-231.

Volle J, Yu X, Sun H, Tanninen SE, Insel N, Takehara-Nishiuchi K (2016) Enhancing Prefrontal Neuron Activity Enables Associative Learning of Temporally Disparate Events. Cell Reports 15:2400-2410.

Whitaker LR, Hope BT (2018) Chasing the addicted engram: identifying functional alterations in fos-expressing neuronal ensembles that mediate drug-related learned behavior. Learn Mem 25:455-460.

Whitaker LR, Carneiro de Oliveira PE, McPherson KB, Fallon RV, Planeta CS, Bonci A, Hope BT (2016) Associative learning drives the formation of silent synapses in neuronal ensembles of the nucleus accumbens. Biol Psychiatry 80:246-256.

Whitaker LR, Warren BL, Venniro M, Harte TC, McPherson KB, Beidel J, Bossert JM, Shaham Y, Bonci A, Hope BT (2017) Bidirectional modulation of intrinsic excitability in rat prelimbic cortex neuronal ensembles and nonensembles after operant learning. J Neurosci 37:8845-8856.

Yiu AP, Mercaldo V, Yan C, Richards B, Rashid AJ, Hsiang HL, Pressey J, Mahadevan V, Tran MM, Kushner SA, Woodin MA, Frankland PW, Josselyn SA (2014) Neurons are recruited to a memory trace based on relative neuronal excitability immediately before training. Neuron 83:722-735.

Zhang Z, Ferretti V, Güntan I, Moro A, Steinberg EA, Ye Z, Zecharia AY, Yu X, Vyssotski AL, Brickley SG, Yustos R, Pillidge ZE, Harding EC, Wisden W, Franks NP (2015) Neuronal ensembles sufficient for recovery sleep and the sedative actions of $\alpha 2$ adrenergic agonists. Nat Neurosci 18:553-561.

Ziminski JJ, Hessler S, Margetts-Smith G, Sieburg MC, Crombag HS, Koya E (2017) Changes in appetitive associative strength modulates nucleus accumbens, but not orbitofrontal cortex neuronal ensemble excitability. J Neurosci 37:3160-3170. 